\title{
Ebolavirus and Marburgvirus: Insight the Filoviridae family
}

\author{
Paolo Ascenzi ${ }^{\text {a,1 }}$, Alessio Bocedi ${ }^{\text {a,1 }}$, Julia Heptostall ${ }^{\text {a,1, }}$, \\ Maria Rosaria Capobianchi ${ }^{\mathrm{a}}$, Antonino Di Caro ${ }^{\mathrm{a}}$, Eloise Mastrangelo ${ }^{\mathrm{b}}$, \\ Martino Bolognesi ${ }^{\mathrm{b}}$, Giuseppe Ippolito ${ }^{\mathrm{a}, *}$ \\ a National Institute for Infectious Diseases I.R.C.C.S. 'Lazzaro Spallanzani', Via Portuense 292, I-00149 Roma, Italy \\ ${ }^{\mathrm{b}}$ C.N.R.-I.N.F.M. and Department of Biomolecular Sciences and Biotechnology, University of Milano, Via Celoria 26, I-20131 Milano, Italy \\ Received 3 August 2007; accepted 28 September 2007
}

\begin{abstract}
Ebolavirus and Marburgvirus (belonging to the Filoviridae family) emerged four decades ago and cause epidemics of haemorrhagic fever with high case-fatality rates. The genome of filoviruses encodes seven proteins. No significant homology is observed between filovirus proteins and any known macromolecule. Moreover, Marburgvirus and Ebolavirus show significant differences in protein homology. The natural maintenance cycle of filoviruses is unknown, the natural reservoir, the mode of transmission, the epidemic disease generation, and temporal dynamics are unclear. Lastly, Ebolavirus and Marburgvirus are considered as potential biological weapons. Vaccine appears the unique therapeutic frontier. Here, molecular and clinical aspects of filoviral haemorrhagic fevers are summarized.
\end{abstract}

(c) 2007 Published by Elsevier Ltd.

Keywords: Ebolavirus; Marburgvirus; Viral genome; Viral proteins; Lethal haemorrhagic fever; Infection; Epidemiology; Pathogenesis; Clinical features and management; Prevention and control; Therapy; Vaccine; Biodefence

\section{Contents}

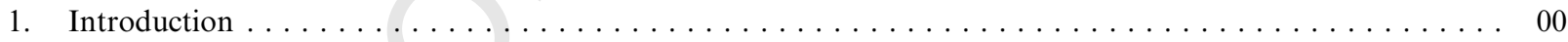

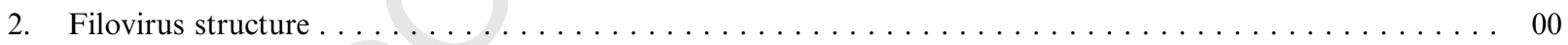

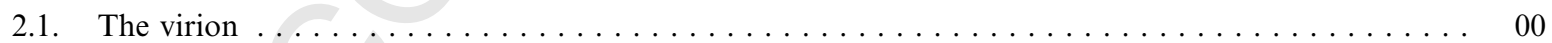

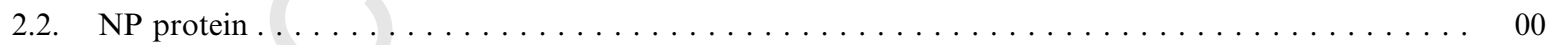

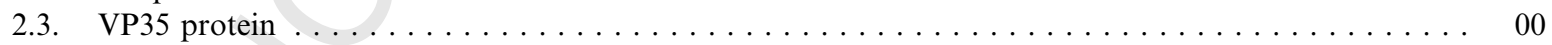

Abbreviations: dsDNA, double-strand DNA; GP, surface glycoprotein; IFN, interferon; L protein, RNA-dependent RNA polymerase; MVB, multi-vesicular body; NP, nucleoprotein; ssRNA, single-strand RNA; TM, transmembrane; VEE, Venezuelan equine encephalitis; VLP, virus-like particle; VP, viral protein; VP24, viral protein 24; VP30, viral protein 30; VP35, viral protein 35; VP40, viral protein 40; VSV, Vesicular stomatitis virus.

This paper is dedicated to the memory of our friend and colleague Fabrizio Poccia who prematurely died on June 12 th 2007.

* Corresponding author. Tel.: +3906 5594223; fax: +39065594224.

E-mail address: ippolito@inmi.it (G. Ippolito).

${ }^{1}$ These authors contributed equally to this paper. 


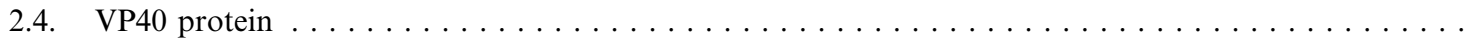

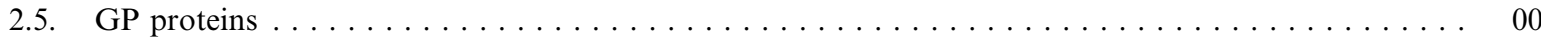

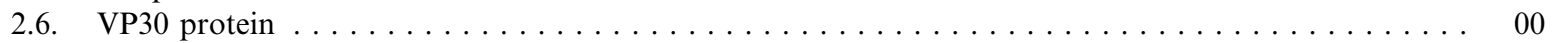

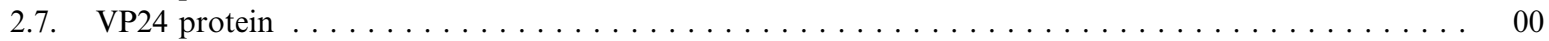

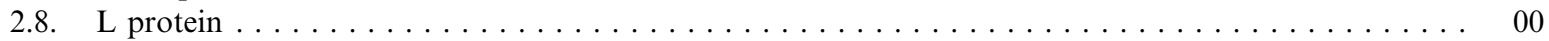

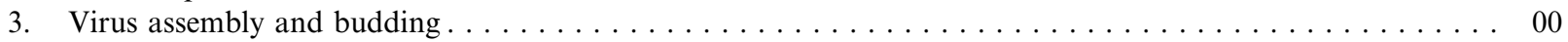

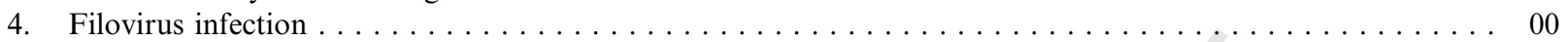

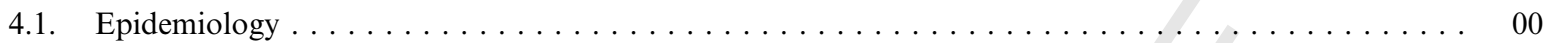

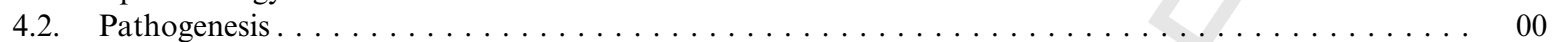

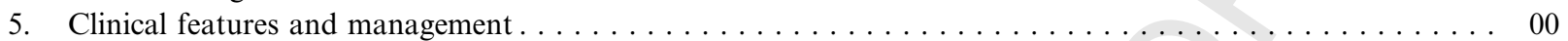

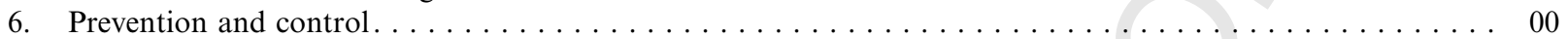

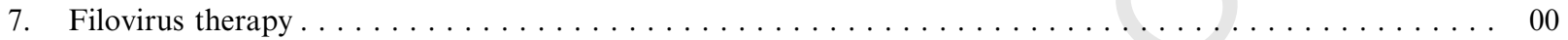

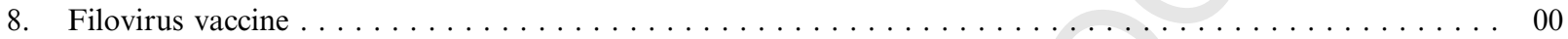

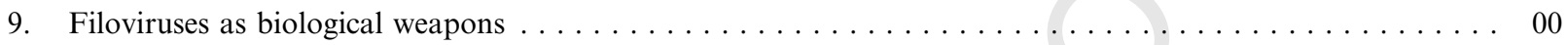

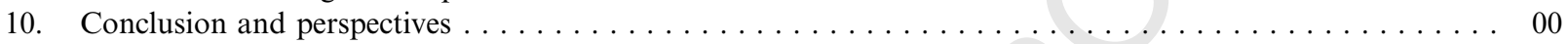

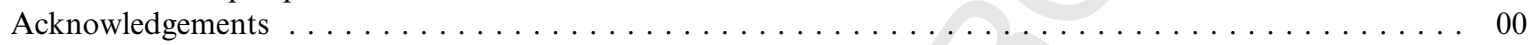

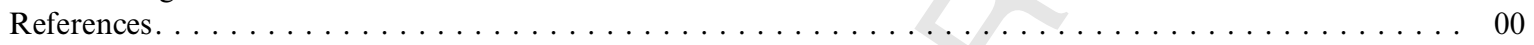

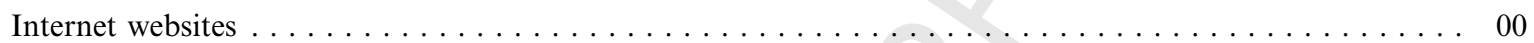

\section{Introduction}

Mononegavirales, or 'non-segmented negative-strand RNA viruses', are enveloped viruses that have genomes consisting of a single-strand RNA (ssRNA) molecule of negative sense. The Mononegavirales order includes the Rhabdoviridae, Paramyxoviridae, Filoviridae, and Bornaviridae families. Although these viruses, of high medical and economical relevance, have different hosts and distinct morphological and biological properties, the typical mode of replication and gene expression has been retained. This suggests that they have originated from a common ancestor (see Conzelmann, 2004).

Ebolavirus and Marburgvirus are two genera of negative-sense ssRNA viruses, which together make up the family Filoviridae. Nowadays, there are five known species of filovirus (Zaire ebolavirus, Sudan ebolavirus, Ivory Coast ebolavirus, Reston ebolavirus, and Lake Victoria marburgvirus) and nineteen recognised strains (thirteen of Ebolavirus and six of Marburgvirus) (Table 1) (http://www.ncbi.nlm.nih.gov/ICTVdb/ICTVdB). The family name comes from the Latin filum, meaning 'thread' or 'filament', reflecting the morphology of the virus particles on electron microscopy. The names 'Ebola' and 'Marburg' come from the river Ebola, in Sudan and Zaire, where one of the first registered outbreaks of the disease occurred and from the town of Marburg, in Germany, where the first known outbreaks of Filoviridae diseases occurred and where Filoviridae have been discovered (see Feldmann and Klenk, 1996; Pigott, 2005).

Marburgvirus and Ebolavirus cause severe haemorrhagic illness in humans, for which there is no effective specific treatment (see Takada and Kawaoka, 2001; Mahanty and Bray, 2004; Pigott, 2005; Hoenen et al., 2006a). Marburgvirus was identified in 1967 when imported non-human primates introduced the agent to several European vaccine production facilities (Siegert et al., 1967). Ebolavirus was recognised in Central Africa in 1976 (Johnson et al., 1977), and all the outbreaks have occurred in that region (see Mahanty and Bray, 2004) (Fig. 1). The natural reservoir, the mode of transmission to hominids and pongids, the epidemic diseases generation, and temporal dynamics remain unclear. Plants, arthropods, reptiles, and small mammals (e.g., bats and rodents) are potential reservoirs (see Arata and Johnson, 1978; Germain, 1978; Murphy and Peters, 1998; Leirs et al., 1999; Isaäcson, 2001; Feldmann et al., 2004; Peterson et al., 2004a; Leroy et al., 2005; Wong et al., 2007).

Recent resurgence in research, fuelled by funding generated by the fear that filoviruses would make effective biological weapons (see Borio et al., 2002; Bray, 2003; Leffel and Reed, 2004; Salvaggio and Baddley, 2004; Paragas and Geisbert, 2006; Hoenen et al., 2006a), has led to a better understanding of the viruses and to the development of countermeasures including vaccines (see Feldmann et al., 2003, 2005; Geisbert and Jahrling, 2003; Hensley et al., 2005; Warfield et al., 2005; Paragas and Geisbert, 2006; Stroher and Feldmann, 2006; Bausch and Geisbert, 2007).

Here, molecular and clinical aspects of filoviral haemorrhagic fevers are summarized. 
Table 1

Species and strains of the Genus Ebolavirus and Marburgvirus ${ }^{\mathrm{a}}$

\begin{tabular}{ll}
\hline Species & Strains \\
\hline Ivory Coast ebolavirus & Ivory Coast (Tai Forest, 1994) \\
Reston ebolavirus & Reston (1989) \\
& Philippine (1989) \\
Siena (1992) & Texas (1996) \\
Sudan ebolavirus & Boniface (1976) \\
& Maleo (1979) \\
Zaire ebolavirus & Eckron (Zaire, 1976) \\
& Gabon (Zaire, 1994-1997) \\
& Kikwit (Zaire, 1995) \\
& Mayinga (Zaire, 1976) \\
& Tandala (Zaire, 1977) \\
Lake Victoria marburgvirus & Zaire (Zaire, 1976) \\
& Marburg Ravn (Kenya, 1987) \\
& Musoke (Kenya, 1980) \\
& Ozolin (Zimbabwe, 1975) \\
& Popp (West Germany, 1967) \\
& Ratayczak (West Germany, 1967)
\end{tabular}

\footnotetext{
${ }^{a}$ Modified from http://www.ncbi.nlm.nih.gov/ICTVdb/ICTVdB.
}

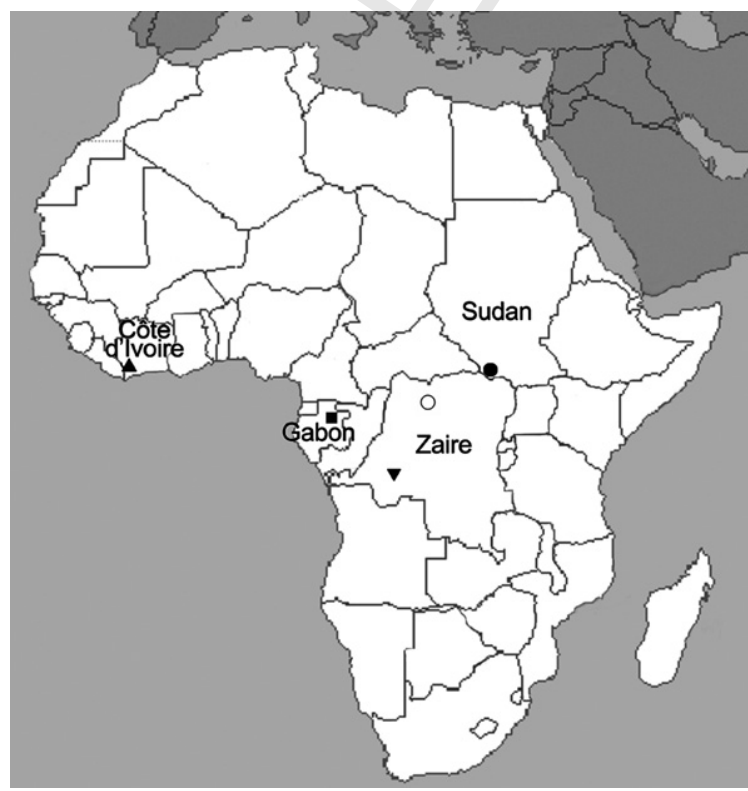

Fig. 1. Map of Ebola outbreaks in Africa. Bumba (○), Maridi and Yambio from http://virus.stanford.edu/filo/history.html.

\section{Filovirus structure}

\subsection{The virion}

Filovirus virions have a complex construction and consist of an envelope, a nucleocapsid, a polymerase complex, and a matrix. Virions are enveloped, filamentous, or pleomorphic with extensive branching or 
U-shaped or 6-shaped, about $80 \mathrm{~nm}$ in diameter, greatly variable up to $1400 \mathrm{~nm}$ long (Fig. 2). The surface projections are distinctive knob-shaped peplomers evenly covering the surface. They are spaced widely apart, evenly dispersed and embedded in a lipid bilayer. The surface projections comprise surface glycoproteins (GPs) and are composed of one type of protein. Surface projections are $10 \mathrm{~nm}$ long and spaced $10 \mathrm{~nm}$ apart. The nucleocapsid exhibits helical symmetry, is cross-striated, and is $50 \mathrm{~nm}$ in diameter. Axial canal is distinct, is $20 \mathrm{~nm}$ in diameter, and is helical-shaped, the pitch of helix is $5 \mathrm{~nm}$ (see Feldmann and Klenk, 1996; Jasenosky and Kawaoka, 2004; Hartlieb and Weissenhorn, 2006).

The viral genome is coding for structural and non-structural proteins (VPs). The core of the virion consists of the RNA genomic molecule, of the nucleoprotein (NP) that binds the genomic RNA, and of the nucleocapsid viral protein 30 (VP30). They are linked by matrix viral proteins 24 and 40 (VP24 and VP40, respectively) to the inner surface of the lipid bilayer of the viral envelope. The viral protein 35 (VP35) and the viral polymerase L (L) are also present in the core of the virion. The envelope glycoprotein GP, anchored to the viral bilayer, forms the viral spikes driving host recognition (Fig. 2). Lipids are present and are located in the envelope. The composition of viral lipids and host cell membranes are similar. The lipids are of host origin and are derived from plasma membranes (see Takada and Kawaoka, 2001; Jasenosky and Kawaoka, 2004; Hartlieb and Weissenhorn, 2006).

Comparison of Filoviridae genomes with other Mononegavirales demonstrates a similar structure and suggest comparable mechanisms of transcription and replication (Fig. 2). However, comparative sequence analyses of single genes indicate that Filoviridae are phylogenetically quite distinct from other families of the order Mononegavirales (see Feldmann and Klenk, 1996; Jasenosky and Kawaoka, 2004; Hartlieb and Weissenhorn, 2006).

The genome constitutes $1.1 \%$ of the virion by weight. The genome is not segmented and consists of a single molecule of linear, negative-sense ssRNA. The Ebolavirus and Marburgvirus genome consists of a single about $19 \mathrm{~kb}$ strand of negative-sense RNA (http://www.ncbi.nlm.nih.gov/entrez/query.fcgi?CMD= search\&DB=pubmed). The genome cannot be transcribed or copied by host-cell enzymes, all the molecular pattern required for viral replication is carried within the virion. Transcription begins at the $3^{\prime}$-end and pro-
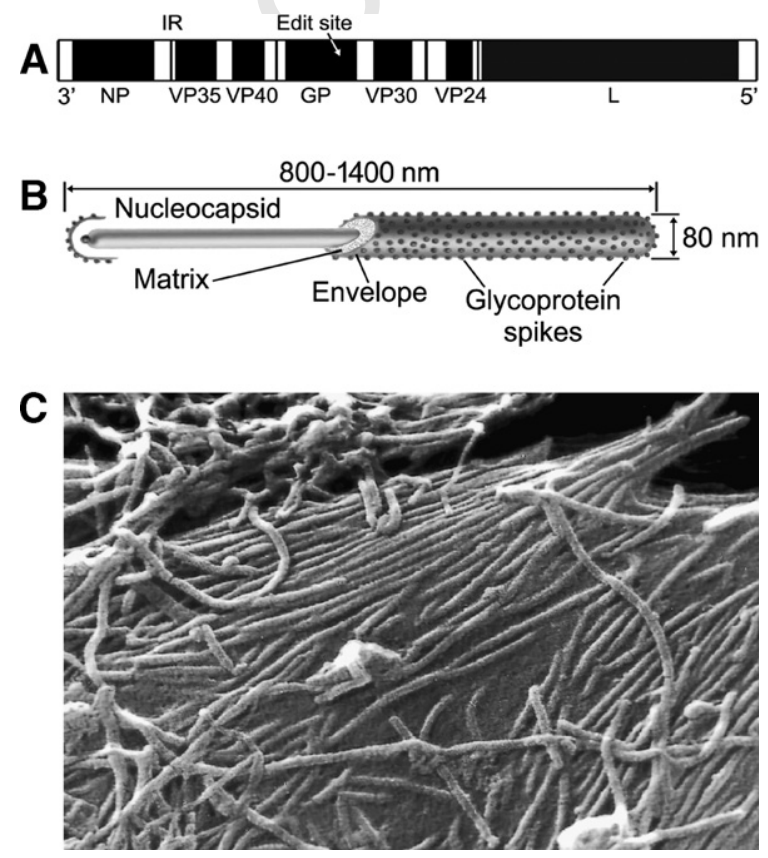

Fig. 2. Zaire ebolavirus. (Panel A) Arrangement of the seven filovirus genes along the single stranded negative-sense RNA genome. Vertical lines indicate the intergenic regions (IR). (Panel B) Structure of a filovirus virion. (Panel C) Scanning electron micrograph of Ebola virus-infected cell showing numerous virions on the cell surface. Modified from Mahanty and Bray (2004) and http:// www.ncbi.nlm.nih.gov/ICTVdb/Images/Murphy/ebola_cell.htm. 
duces from seven to nine individual mRNAs. Nucleotide sequences at the $3^{\prime}$-terminus are complementary to similar regions on the $5^{\prime}$-end. The $5^{\prime}$-end of the negative-sense strand does not have a covalently attached terminal protein. Moreover, the $5^{\prime}$-end of the genome does not have cap. The $3^{\prime}$-terminus has conserved nucleotide sequences (leader), in genera of same family. Furthermore, the $3^{\prime}$-terminus has no poly(A) tract. The single coding ssRNA may give the transcriptional information for three forms of the envelope glycoprotein differing in length (i.e., three distinct mRNAs). Intergenic regions contain initiation and termination signals (see Feldmann and Klenk, 1996; Jasenosky and Kawaoka, 2004; Mahanty and Bray, 2004; Ecker et al., 2005; Ndayimirije and Kindhauser, 2005; Hartlieb and Weissenhorn, 2006).

The amino acid identity within Ebolaviruses ranges between $55 \%$ and $80 \%$. The amino acid identity within Ebolaviruses and Marburgvirues ranges between 24\% and $46 \%$. Strikingly, the amino acid identity between Ebolaviruses and Marburgviruses VP40, is $25 \%$ only (Table 2). This agrees with distinct mechanisms of entry of Marburgvirus and Ebolavirus despite causing similar diseases (see Chan et al., 2000).

Table 2

Amino acid sequence identity within Ebolaviruses and Marburgvirus ${ }^{\mathrm{a}}$

\begin{tabular}{|c|c|c|c|c|}
\hline & Zaire ebolavirus & Reston ebolavirus $(\%)$ & Sudan ebolavirus $(\%)$ & Lake Victoria marburgvirus (\%) \\
\hline \multicolumn{5}{|l|}{ Protein NP } \\
\hline Zaire ebolavirus & - & 67 & 67 & 38 \\
\hline Reston ebolavirus & & - & 66 & 35 \\
\hline Sudan ebolavirus & & & - & 36 \\
\hline Lake Victoria marburgvirus & & & & - \\
\hline \multicolumn{5}{|l|}{ Protein VP35 } \\
\hline Zaire ebolavirus & - & 66 & 67 & 31 \\
\hline Reston ebolavirus & & - & 67 & 32 \\
\hline Sudan ebolavirus & & & - & 31 \\
\hline Lake Victoria marburgvirus & & & & - \\
\hline \multicolumn{5}{|l|}{ Protein VP40 } \\
\hline Zaire ebolavirus & - & 75 & 75 & 25 \\
\hline Reston ebolavirus & & - & 80 & 24 \\
\hline Sudan ebolavirus & & & - & 27 \\
\hline Lake Victoria marburgvirus & & & & - \\
\hline \multicolumn{5}{|l|}{ Protein $\mathrm{GP}^{\mathrm{b}}$} \\
\hline Zaire ebolavirus & - & 57 & 55 & 28 \\
\hline Reston ebolavirus & & - & 60 & 26 \\
\hline Sudan ebolavirus & & & - & 27 \\
\hline Lake Victoria marburgvirus & & & & - \\
\hline \multicolumn{5}{|l|}{ Protein VP30 } \\
\hline Zaire ebolavirus & & 68 & 69 & 29 \\
\hline Reston ebolavirus & 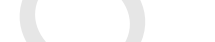 & - & 64 & 28 \\
\hline Sudan ebolavirus & & & - & 29 \\
\hline Lake Victoria marburgvirus & & & & - \\
\hline \multicolumn{5}{|l|}{ Protein VP24 } \\
\hline Zaire ebolavirus & & 81 & 74 & 36 \\
\hline Reston ebolavirus & r & - & 75 & 34 \\
\hline Sudan ebolavirus & & & - & 34 \\
\hline Lake Victoria marburgvirus & & & & - \\
\hline \multicolumn{5}{|l|}{ Protein $\mathrm{L}$} \\
\hline Zaire ebolavirus & - & 73 & 73 & 46 \\
\hline Reston ebolavirus & & - & 73 & 46 \\
\hline Sudan ebolavirus & & & - & 46 \\
\hline Lake Victoria marburgvirus & & & & - \\
\hline
\end{tabular}

${ }^{a}$ Amino acid sequences (from http://www.ncbi.nlm.nih.gov/entrez/query.fcgi?CMD=search\&DB=protein) were selected by BLAST (from http://www.ncbi.nlm.nih.gov/BLAST) and aligned by ClustalW (from http://www.ebi.ac.uk/clustalw/index.html).

b Only protein GP of the Ivory Coast ebolavirus has been sequenced. The identity of the protein GP of the Ivory Coast ebolavirus within Ebolavirus and Marburgvirus ranges between $64 \%$ and $28 \%$. 


\subsection{NP protein}

The central core of Ebolavirus and Marburgvirus consists of the ssRNA genomic molecule and its associated (nucleo)proteins (see Mahanty and Bray, 2004). NP contributes to virus nucleocapsid assembly and budding. The nucleocapsid structure of Ebolavirus appears to be composed of left-handed helices spaced at short intervals, which is structurally consistent with other non-segmented negative-strand RNA viruses (see Huang et al., 2002; Licata et al., 2004; Noda et al., 2005; Noda et al., 2007).

Both the $N$ - and $C$-termini of NP (amino acid residues 2-150 and 601-739, respectively) of Ebolavirus NP are important for NP-NP interaction, for the formation of NP tube structures, and for the incorporation of NP into VLPs. The Ebolavirus NP tube forms a scaffold for the nucleocapsid-like structures. $O$-glycosylation and sialylation of Ebolavirus NP are required for nucleocapsid assembly, the host enzymes involved and the molecular mechanisms are still unclear. Moreover, the $C$-terminus of NP is important for nucleocapsid incorporation into virions. However, the region from amino acid residues 601-739 of NP was not required for nucleocapsid formation or replication of the minigenome. Furthermore, the region from amino acid residues 451-600 of Ebolavirus NP is required for the formation of nucleocapsid-like structures and for replication of the viral genome (see Licata et al., 2004; Watanabe et al., 2006; Noda et al., 2007). Lastly, Marburgvirus NP alone is sufficient to form nucleocapsid-like structures (Kolesnikova et al., 2000; Mavrakis et al., 2002), which suggests that the nucleocapsid structures of these two viruses are different (see Watanabe et al., 2006).

As a whole, given that NP is likely involved in all steps of viral replication after uncoating of the viral genome, a better understanding of the functional region(s) of this protein will provide insight into the Ebolavirus life cycle and its pathogenicity (see Watanabe et al., 2006).

\subsection{VP35 protein}

Ebolavirus VP35, which plays an essential role in viral RNA synthesis, acts as a type 1 interferon (IFN) antagonist (Basler et al., 2000). VP35 was packaged into budding VLPS, VP40, and VP35 being sufficient for packaging an Ebolavirus minigenome RNA into VLPs (Johnson et al., 2006a,b). Moreover, VP35 inhibits virus infection-induced transcriptional activation of the IFN regulatory factor-3-responsive mammalian promoters (Basler et al., 2003) thus inhibiting also the transcriptional activation of type 1 IFN genes. The production of an IFN antagonist might contribute to the pathogenicity of Ebolaviruses, much in the same way as the NS1 protein of highly pathogenic influenza virus strain, another IFN antagonist, enhances the replicative ability of influenza virus (Garcia-Sastre et al., 1998). It is well known that type 1 IFN production and action represent an important arm of the innate immunity, that is also able to regulate the subsequent development of the adaptive immune response. The innate immune system activation is the earliest response to microbial entry and injury and in particular the disruption of the IFN system enhances susceptibility to many microbial infections (Bose and Banerjee, 2006).

VP35 participates to spontaneous nucleocapsid assembly (Huang et al., 2002) and could be required for full expression of virulence (Takada and Kawaoka, 2001). Moreover, VP35 counteracts the antiviral action of IFN by its ability to suppress the pathway regulated by double-strand RNA-(dsRNA-)dependent protein kinase PKR. The VP35 protein interferes with one or more components of the IFN pathways, which facilitates rapid spread and dissemination of Ebola virus, therefore VP35 protein functions also at a step after IFN production (see Feng et al., 2007).

Ebola virus is insensitive to IFN, although phosphorylation of STAT1 and STAT2, an early event of the type 1 IFN signaling, was not affected (Jahrling et al., 1999; Kash et al., 2006). This raises the possibility that Ebola virus blocks one or more steps after STAT phosphorylation, VP35 protein may be required to overcome the antiviral action of IFN during Ebola virus infection. Furthermore, to inhibit the IFN system, VP35 counteracts the activity of PKR, a key component in mediating the IFN-induced antiviral response (Gale et al., 1998). In response to virus infection, PKR forms a homodimer and become phosphorylate on multiple Ser, Thr, and Tyr residues (Gale et al., 1998; Dey et al., 2005; Su et al., 2006). These events convert PKR into an active enzyme that phosphorylates also the $\alpha$ subunit of the eIF $2 \alpha$ translation initiation factor. Suggesting that in cells infected with Ebolavirus, VP35 may serve to block the activation of PKR and thereby abrogate this 'first line' of host defense. Note that the inhibition of the PKR response by VP35 provides a favorable 
environment for viral infection. Although the detailed mechanism by which VP35 acts is elusive, it is believed that dsRNA produced in virus-infected cells is the activator of PKR. VP35 may act as a decoy of dsRNA thus acting also in the inhibition of type 1 IFN production, that is triggered by more than one cellular dsRNA sensors acting via the activation of IRF-3 transcription factor (see Feng et al., 2007).

The $N$-terminus of VP-35 is required to inhibit the PKR activity and the expression of $\beta$ IFN gene. It is noteworthy that the region containing amino acids $82-118$ is predicted to form a coiled-coil domain, which is required for the oligomerization of VP35 (Reid et al., 2005). This raises the possibility that oligomerization of VP35 plays a role not only in blocking IFN production but also in the PKR response. The $C$-terminus of VP35 is involved in blocking activation of IFN regulatory factor-3, which stimulates the synthesis of $\beta$-IFN (Basler et al., 2003; Hartman et al., 2004; Reid et al., 2005; Cardenas et al., 2006; Hartman et al., 2006).

As a whole, the fact that the Ebolavirus VP35 interferes with PKR activity suggests that this function may contribute to the pathogenesis of Ebolavirus infection (see Johnson et al., 2006a; Feng et al., 2007).

\subsection{VP40 protein}

Viral matrix proteins from negative-strand RNA viruses participate in the assembly of lipid-enveloped viruses by providing a link between the surrounding membrane and the nucleocapsid structure (see Geisbert and Jahrling, 1995; Jasenosky and Kawaoka, 2004; Morita and Sundquist, 2004; Schmitt and Lamb, 2004; Hartlieb and Weissenhorn, 2006; Watanabe et al., 2006). VP40, the most abundant matrix protein in Ebolavirus and Marburgvirus particles, is positioned beneath the viral bilayer to ensure the structural integrity of the particle (Geisbert and Jahrling, 1995), plays an important role in virus assembly and budding (see Garoff et al., 1998; Hartlieb and Weissenhorn, 2006; Jasenosky and Kawaoka, 2004; Licata et al., 2004; Morita and Sundquist, 2004; Schmitt and Lamb, 2004; Watanabe et al., 2006), and interacts preferentially with bilayers with elevated levels of negatively charged phospholipids in vitro (Ruigrok et al., 2000a). Moreover, VP40 is involved either in viral or host cell RNA metabolism during the replication cycle as suggested by its capability of sequestering host RNA (Gomis-Ruth et al., 2003). Lastly, VP protein is capable of eliciting protective immune responses to Zaire ebolavirus, this indicates that they may be important components of a vaccine designed to protect humans from Ebola haemorrhagic fever (Wilson et al., 2001).

The Zaire ebolavirus matrix protein VP40 is topologically distinct from all other known viral matrix proteins (Dessen et al., 2000). Monomeric VP40 (Asn31-Lys326) is an elongated protein consisting of two domains with unique folds connected by a flexible linker (Fig. 3, Panel A, and Table 3). The $N$-terminal domain is folded into a $\beta$-sandwich consisting of six antiparallel $\beta$-strands arranged in two $\beta$-sheets of three strands each. The $C$-terminal domain consists of one antiparallel triple-stranded $\beta$-sheet and an opposite set of three $\beta$-strands which form a strongly bent $\beta$-sheet. In both domains, the $\beta$-strand shows a concave twist, and an $\alpha$-helix packs laterally with respect to the $\beta$-sheets. The matrix protein VP40 domains are not tightly packed against each other, the interdomain region contains a zipper of hydrophobic residues. Most of the residues corresponding to this hydrophobic stretch are conserved between Ebolavirus and Marburgvirus VP40 sequences (Dessen et al., 2000).

The VP40 undergoes dimerization by contacts within the $N$-terminal domains (Fig. 3, Panel B, and Table 3) (the monomers forming the dimer are named A and B, according to Gomis-Ruth et al., 2003). The dimer is stabilized by salt bridges from Glu160A to Arg148B and Arg151B, respectively. Moreover, polar interactions are found between Trp95A and Gln184B. The stability of the dimer is enhanced by hydrophobic core interactions (residues Trp95, Pro97, Phe161, Ile74, and Ile82 from molecules A and B) as well as residues Ala189Asp194 (from molecules A and B), which interact in an extended conformation on the outside of the ring with a neighboring molecule (Gomis-Ruth et al., 2003). All polar residues except Glu160, which is substituted by Asn, and all of the hydrophobic residues involved in the stabilization of the interface are conserved between VP40 sequences from Ebolavirus and Marburgvirus (Dessen et al., 2000). The interface of the antiparallel dimer coincides with the interface occupied by the $N$ - and $C$-terminal domains in the closed monomeric conformation, and residues covered by both interfaces are approximately the same (Dessen et al., 2000; GomisRuth et al., 2003). This indicates that the C-terminal domain has to move away to allow the formation of the dimer as suggested (Scianimanico et al., 2000). 


JMAM 321 ARTICLE IN PRESS No. of Pages 35, Model 3+
1 November 2007; Disk Used
$8 \quad$ P. Ascenzi et al. / Molecular Aspects of Medicine $x x x$ (2007) xxx-xxx

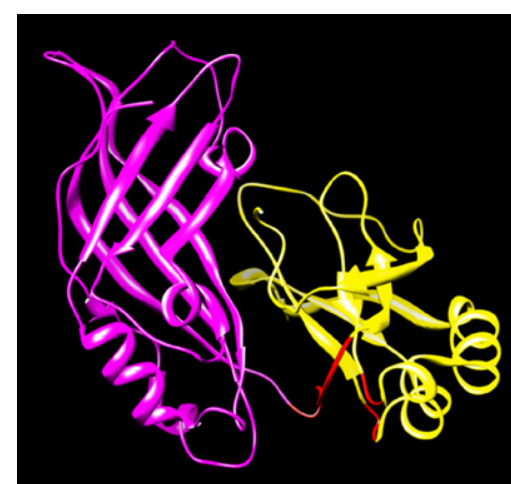

A

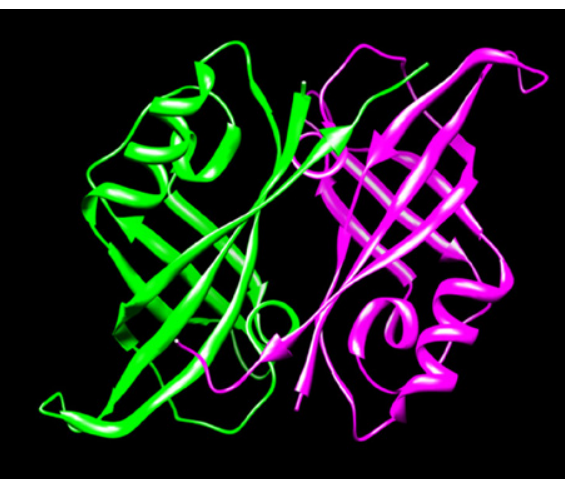

$\mathrm{B}$

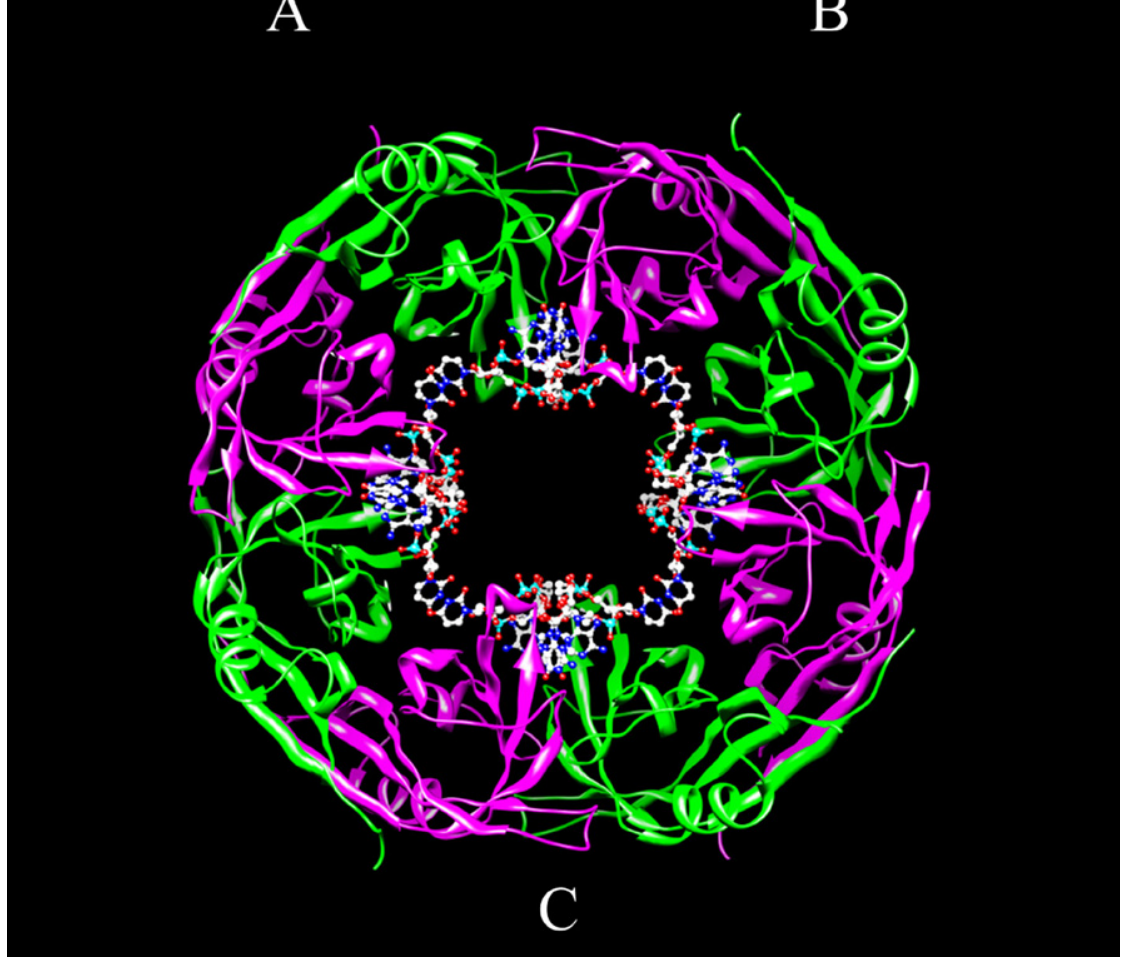

Fig. 3. Zaire ebolavirus VP40 protein structure. (Panel A) Ribbon diagram of VP40 monomeric structure. $N$-terminal and $C$-terminal domain are shown in magenta and yellow respectively. Flexible loop regions without defined electron density maps are in red (PDB ID: 1ES6; Dessen et al., 2000). (Panel B) Ribbon diagram of the antiparallel dimer formed by the $N$-terminal domain of two VP40 monomers. The two monomers are shown in magenta and green (PDB ID: 1H2D; Gomis-Ruth et al., 2003). (Panel C) Ribbon diagram of the ring octameric structure of VP40 protein (subunits are in magenta and green). The RNA molecule, bound at the dimer-dimer interface, is shown in ball-and-stick (PDB ID: 1H2D; Gomis-Ruth et al., 2003). Molecular graphics images were produced using the UCSF Chimera package (Pettersen et al., 2004). (For interpretation of the references to colour in this figure legend, the reader is referred to the web version of this article.)

Ebolavirus VP40 (Asn31-Asp194 and Asn31-Lys212) octamers have been detected in vivo (Gomis-Ruth et al., 2003). However, VP40 hexamerization might play a role in Ebolavirus assembly, as reported for HIV-1 and SIV (Dessen et al., 2000). To undergo octamerization, the VP40 N-terminal domain (Asn31Pro187) has to unfold allowing the formation of the dimer-dimer interface, of the RNA binding pocket, and the interaction with cellular budding factors. Then, the $C$-terminal domain (Leu203-Lys326) moves out of its position to facilitate the formation of the dimer and the association to the membrane. The octameric ring structure is composed of four dimers, the $N$ - and $C$-terminal ends are at the outer side of the ring (Fig. 3, Panel C, and Table 3) (Gomis-Ruth et al., 2003). 
Table 3

Three-dimensional structures of Filoviridae proteins available on the RCSB Protein Data Bank ${ }^{\mathrm{a}}$

\begin{tabular}{llll}
\hline PDB Code & Virus & Protein & Ref. \\
\hline 1ES6 & Zaire ebolavirus & VP40 & Dessen et al. (2000) \\
1H2C & Zaire ebolavirus & VP40 & Gomis-Ruth et al. (2003) \\
1H2D & Zaire ebolavirus & VP40 & Gomis-Ruth et al. (2003) \\
1EBO & Zaire ebolavirus & GP & Weissenhorn et al. (1998) \\
2EBO & Zaire ebolavirus & GP & Malashkevich et al. (1999) \\
2I8B & Zaire ebolavirus & VP30 & Hartlieb et al. (2007) \\
\hline
\end{tabular}

${ }^{a}$ Modified from Berman et al. (2000).

In octameric VP40, the dimer-dimer interactions (involving molecules A and C, according to Gomis-Ruth et al., 2003) are dominated by hydrophobic interactions complemented with polar main chain contacts, including hydrogen bonds between the amide of Gly141A and the carbonyl of Tyr171C, and the oxygen of Thr173A and the amide of Gly139C. In addition, residues from the loop structure connecting $\beta$-strand 4 and $\alpha$-helix 3 are sandwiched between two loop structures from a neighboring molecule, namely one connecting $\beta$-strands 1 and 2 and the other one bridging $\alpha$-helix 4 with $\beta$-strand 6 (Gomis-Ruth et al., 2003).

A single-strand ribonucleotide segment $5^{\prime}-\mathrm{U}-\mathrm{G}-\mathrm{A}-3^{\prime}$ from the expression host Escherichia coli binds to the dimer-dimer interface (Fig. 3, Panel C, and Table 3). Both ssRNA termini are pointing into the interior of the pore, being accessible for bulk solvent and, putatively, for 3'- and/or 5'-elongated RNA molecules. The main specificity of the observed trinucleotide binding resides in the central guanosine phosphate. The guanine base interacts mainly with Arg134 and Phe125 of one protein chain. The backbone phosphate group of $\mathrm{G}$ is linked via a double-headed salt bridge with Arg134 of the symmetry-related polypeptide, while the sugar moiety contacts the protein main chain. Remarkably, all polar residues involved in the RNA interaction are strictly conserved between Ebolavirus and Marburgvirus VP40 sequences and some van der Waals contacts are substituted by conservative changes (Gomis-Ruth et al., 2003). Phe125Ala mutation resulted in reduced RNA binding, and Arg134Ala mutation completely abolished RNA binding and thus octamer formation.

In conclusion, RNA binding of VP40 and therefore octamer formation are essential for the Ebola virus life cycle (Hoenen et al., 2005). The two oligomeric conformations play a central roles in the Ebolavirus life cycle, the hexamer model suggests that the monomer-hexamer transition involves a conformational change(s) in the $N$-terminal domain that is not evident during octamerization (Nguyen et al., 2005). The three different conformations of VP40 (monomeric, hexameric, and octameric) are the prime examples of how viral genomes with a limited capacity can encode for protein conformations that probably exert different tasks (see Morita and Sundquist, 2004; Schmitt and Lamb, 2004; Hartlieb and Weissenhorn, 2006).

\subsection{GP proteins}

Ebola virions possess a single surface transmembrane (TM) GP that plays a central role in virus attachment and entry (by interaction of the GP signal peptide with cellular lectins), cell rounding, cytotoxicity, down-regulation of host surface proteins, and enhancement of virus assembly and budding (see Takada and Kawaoka, 2001; Chandran et al., 2005; Manicassamy et al., 2005; Alazard-Dany et al., 2006; Bär et al., 2006; Han et al., 2007; Manicassamy et al., 2007; Marzi et al., 2006a,b). Ebolavirus GP toxicity is contributed by a dynamindependent protein-trafficking pathway and a ERK mitogen-activated protein kinease pathway (Sullivan et al., 2005; Zampieri et al., 2007). However, GP is a component of the vaccine that has successfully protected nonhuman primates against Ebolavirus haemorrhagic fever (Sullivan et al., 2003). Moreover, Zaire ebolavirus GP represents a target for the cyanobacterial protein cyanovirin-N which impairs virus infection both in vitro and in vivo (Barrientos et al., 2003).

Gene four of the Ebolavirus genome encode for the precursors of a soluble non-structural glycoprotein (pre-sGP) and the structural TM glycoprotein (pre-GP) (see Dolnik et al., 2004; Falzarano et al., 2006).

Pre-sGP is the primary product and is processed by signalase and furin cleavage into the 291 amino-acid long $N$-terminal fragment, sGP, and the 41 amino-acid long $C$-terminal fragment, $\Delta$-peptide. Both sGP and 
$\Delta$-peptide are secreted from infected cells and sGP has been detected in the serum of infected individuals (see Dolnik et al., 2004; Falzarano et al., 2006).

Similarly, pre-GP (a single chain precursor of 676 amino acids) is co- and post-translationally processed by a signalase and furin into mature disulfide-linked fragments GP1 (Met1-Arg501) and GP2 (Glu502-Phe676). Instability of the GP1-GP2 complex during intracellular transport and processing might lead to the release of GP1. In addition, plasma membrane-associated GP1-GP2 is cleaved by a metalloprotease, which leads to the shedding of an anchor-minus form, designated GP1-GP2 $\Delta$ TM. While sGP shares the $295 \mathrm{~N}$-terminal amino acids with GP1, GP1-GP2 $\Delta$ TM and GP1-GP2, its 28 amino acid $C$-terminus is unique due to RNA editing, which allows expression of the TM glycoprotein GP1-GP2 and its related products (see Dolnik et al., 2004; Falzarano et al., 2006).

While the two proteins share a considerable amount of primary sequence they have markedly different quaternary structures, with sGP forming homodimers while GP1-GP2 forms trimers (see Dolnik et al., 2004; Falzarano et al., 2006).

sGP is secreted as a disulfide-linked parallel homodimer, containing Cys53-Cys53' and Cys306-Cys306' disulfide bonds and five glycosylated sites. Disulfide bridges are critical for the proposed anti-inflammatory function of sGP (see Falzarano et al., 2006).

GP1 is responsible for binding to cell-surface receptors, whereas GP2 is responsible for mediating membrane fusion. Interestingly, GP1 is also shed in soluble form from infected cells (see Fields et al., 1996; Volchkov et al., 1998; Takada and Kawaoka, 2001; Manicassamy et al., 2005). Interestingly, cleavage of GP by endosomal cathepsin-B and -L triggers fusion and infection (see Chandran et al., 2005; Schornberg et al., 2006).

The $N$-terminal region of GP1 is responsible for viral entry being implicated in cell receptor binding. Moreover, this GP1 region is involved in the proper folding and/or overall conformation of GP. Notably, sequence comparison of the GP1 proteins suggests that the majority of the critical residues for GP folding and viral entry identified in Ebola virus GP1 are conserved in Marburgvirus (Manicassamy et al., 2005).

The GP2 monomer contains a 44-residue $N$-terminal $\alpha$-helix (Asp552-Gln595) followed by a 19-residue link (Arg596-Asp614) and a short antiparallel $\alpha$-helix (Trp615-Asp632) (Fig. 4, Panels A and C, and Table 3). The Leu585-Ile610 sequence, containing the Cys601-Cys608 disulfide-bonded loop, is homologous to an immunosuppressive sequence found in many retrovirus TM subunits. The conformation of this segment is very similar to that of the homologous sequence in the structure of the Murine Moloney Leukemia virus TM subunit (Volchkov et al., 1992; Fass et al., 1996; Weissenhorn et al., 1998; Malashkevich et al., 1999).

GP2 forms a trimer, each of the three polypeptide chains folds into a helical-hairpin conformation, in which two antiparallel helices are connected by a loop region (Fig. 4, Panels B and D, and Table 3 ) The $N$-terminal helices from each monomer form a central, three-strand coiled coil. This coiled-coil core includes approximately 35 residues (Leu561-Gln595) from each chain. Shorter $C$-terminal helices (Trp615-Asp629) pack in an antiparallel manner into hydrophobic grooves on the surface of the coiled-coil core. In the loop region connecting the $N$ - and $C$-terminal helices, a disulfide bridge between Cys601 and Cys608 links a short $\alpha$-helix (Thr600-Leu604) and a short 310 -helix (Pro606-Ile610). Additionally, the loop region between the $3_{10}$-helix and the $C$-terminal helix (Glu611-Asp614) is in an extended conformation (Weissenhorn et al., 1998; Malashkevich et al., 1999).

A trimeric structure is emerging as a general feature of many viral membrane-fusion proteins from the Zaire ebolavirus, the orthomyxovirus influenza, the lentiviruses HIV-1 and SIV, and the paramxyovirus SV5 (Malashkevich et al., 1999). Then, a model for Zaire ebolavirus fusion to host cell membrane has been hypothesized based on the GP2 trimeric structure. The fusion peptide and the membrane anchor sequences (belonging to GP2) extend toward one end of a thin rod-shaped molecule that could facilitate close apposition of the prefusion membranes. The receptor binding domain (represented by GP1) is attached at the opposite end of the fusion protein rod, where it could be withdrawn from the site of fusion. In this conformation, GP2 could both bridge viral and cell host membranes and facilitate their apposition to initiate membrane fusion (Fig. 5) (Weissenhorn et al., 1998).

Lastly, GP was found to induce a pro-inflammatory response similar to that of LPS (Martinez et al., 2007). the Zaire ebolavirus GP2 trimeric structure may assist in the discovery of agents that prevent infection by Ebo- 


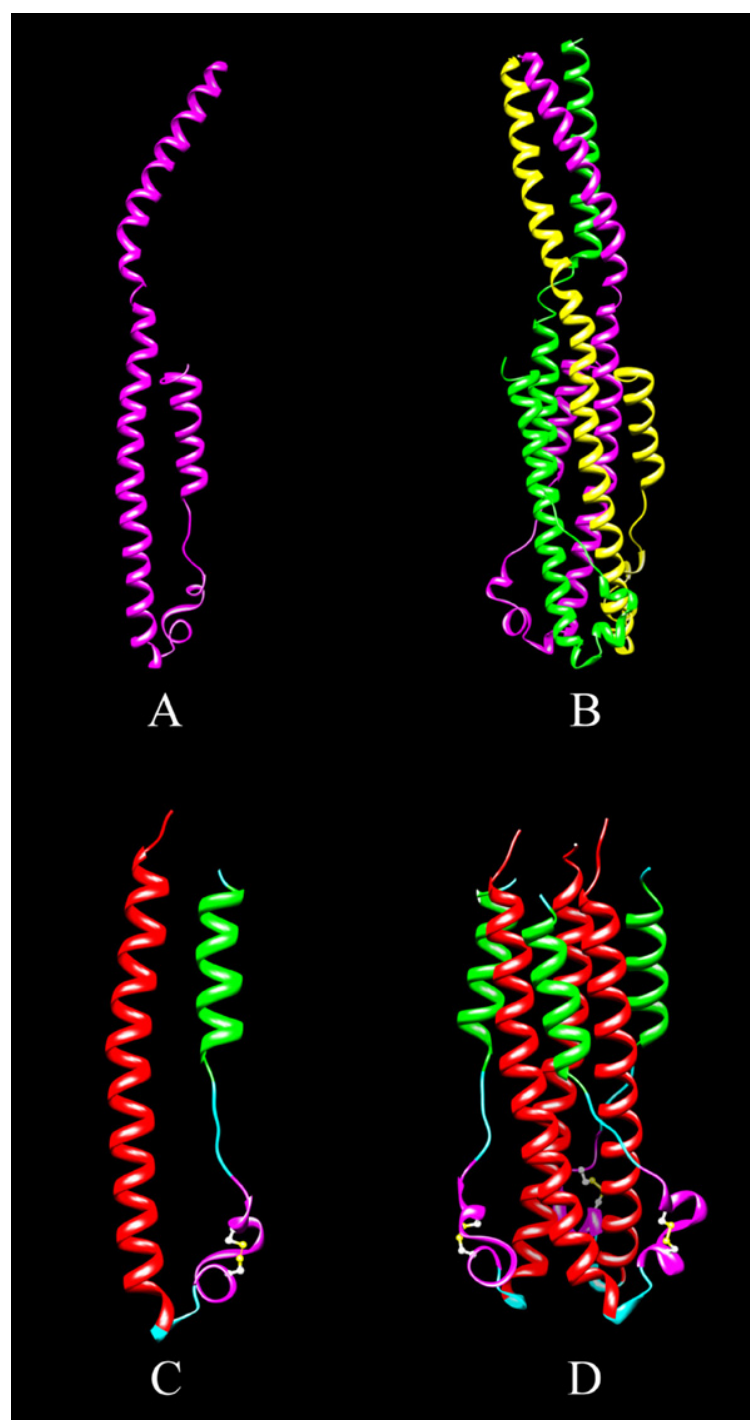

Fig. 4. Zaire ebolavirus GP2 protein structure. (Panel A) Ribbon diagram of hybrid monomeric GP2 (PDB ID: 1EBO; Weissenhorn et al., 1998). (Panel B) Ribbon diagram of hybrid trimeric GP2 (subunits are in magenta, green, and yellow) (PDB ID: 1EBO; Weissenhorn et al., 1998). (Panel C) Ribbon diagram of monomeric GP2. The $N$-terminal helix is shown in red. The $C$-terminal helix is shown in green. The immunosuppressive motif region in oncogenic retroviruses (in magenta) is formed by a short $\alpha$-helix and a short $3_{10}$-helix. The loop regions between the $33_{10}$-helix and the C-terminal helix and between the short $\alpha$-helix and the $N$-terminal helix are in cyan. Disulfide bridges are represented in ball-and-stick (in yellow) (PDB ID: 2EBO; Malashkevich et al., 1999). (Panel D) Ribbon diagram of trimeric GP2. For details, see panel C (PDB ID: 2EBO; Malashkevich et al., 1999). Molecular graphics images were produced using the UCSF Chimera package (Pettersen et al., 2004). (For interpretation of the references to colour in this figure legend, the reader is referred to the web version of this article.)

la virus. Indeed, synthetic peptides corresponding to the $C$-terminal helices of the trimeric structures in HIV-1 or in paramyxoviruses are inhibitors of entry by those viruses (Malashkevich et al., 1999).

\subsection{VP30 protein}

The Ebolavirus genome encodes for several proteins which are necessary for replication and transcription of the viral RNA. Ebolavirus uses a unique transcription stratgey based on the activity of VP30, which is essential for the activation and modulation of the synthesis of viral RNA. In fact, VP30 was shown to act 


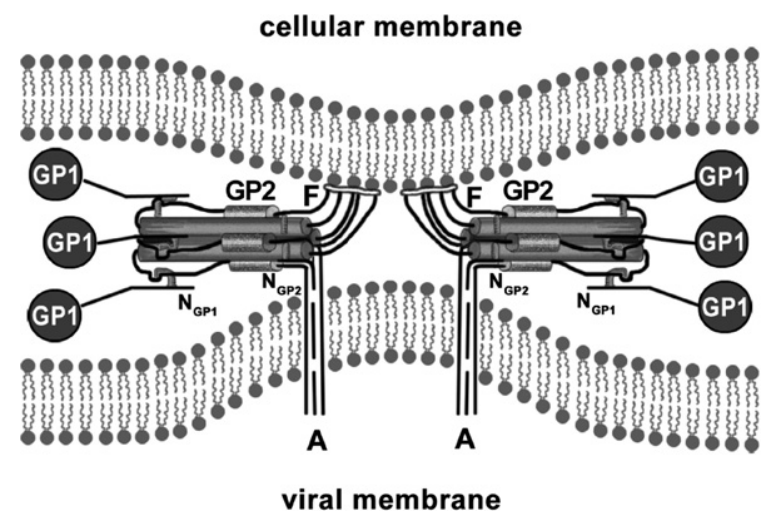

Fig. 5. Hypothetical model for the Zaire virus membrane fusion mechanism. Before fusion, viral GPs projects the receptor-binding domains GP1 towards the cellular membrane. Suddenly, a conformational change of trimeric GP2 extends the $N$-terminal fusion peptides towards the cellular membrane. Then, the outer layer of the fusion has assembled, the $N$-terminal fusion peptides (F) and the $C$-terminal transmembrane anchors (A) lie near each other at a site of close apposition of the prefusion membranes. Flexible links between the rod and the fusion peptide as well as the transmembrane anchors (A) allow variable orientations of the rod with respect to the two membranes. The presence of a second GP protein system indicates how such trimers might aggregate at their hydrophobic ends at initial sites of fusion. $\mathrm{N}_{\mathrm{GP} 1}$, GP1 $N$-terminal; $\mathrm{N}_{\mathrm{GP} 2}$, GP2 $N$-terminal. Modified from Weissenhorn et al. (1998).

by stabilizing nascent RNA. RNA transcription activation depends strongly on the VP30 concentration and phosphorylation state. VP30 binds NP, allowing incorporation into VLPs. Furthermore, VP30 may represent a drug target, small-molecule inhibitors may interfere with VP30 homohexamerization preventing VP30 action (see Mühlberger et al., 1999; Weik et al., 2002; Hartlieb et al., 2003, 2007; John et al., 2007).

Self-assembly of VP30 is essential for viral transcription and propagation. The $C$-terminal domain of the VP30 monomer folds into a compact core helical arrangement consisting of six helices. A seventh helix reaches over to the neighboring monomer by a long linker, allowing both monomers to pack head to head, with no significant structural similarity to known protein structures (Fig. 6, Panel A, and Table 3). The dimerization interface covers about $3.727 \AA^{2}$. The majority of the contacts are polar interactions between side-chain atoms and $\mathrm{C}-\alpha$ backbone amides and carbonyls predominantly between the loop region connecting helices 6 and 7 that nestles into a grove on the neighboring monomer made up by helices 1 and 2 (Fig. 6, Panel B, and Table 3). Since the dimerization is mainly achieved by domain swapping of helix 7, the displacement of helix 7 may be sufficient to modulate VP30 homodimerization (i.e., to disrupt the dimerization observed in the VP30 $C$-terminus and to allow other VP30 conformers). The conservation of these interactions indicates that both Ebolavirus and Marburgvirus VP30 can form such VP30 dimers (see Hartlieb et al., 2007).

The VP30 homodimer might be the building block for the homohexameric active form of VP30 detected in vitro and in infectious Ebolavirus particles. Essential for homooligomerization of VP30 is a region spanning amino acids Ser94-Val112. Within this region, the Leu100-Leu101-Leu102-Leu103 sequence is of critical importance. A second homooligomerization domain is composed of the $C$-terminal half of VP30 (see Hartlieb et al., 2003, 2007).

The VP30 key amino acids involved in RNA binding map to residues 26-40, a region rich in Arg residues. To modulate transcription, VP30 acts in trans with a RNA secondary structure upstream of the first transcriptional start site (John et al., 2007).

NP binding occurs at two VP30 regions, namely a basic cluster around Lys180 and Glu197. VP30-NP recognition may be splitted into two functions. VP30 interacts loosely by its $N$-terminal domain with NP-RNA helical-coil structures that are transcription-competent, without being released in VLPs. However, the interaction of packaged NP-RNA nucleocapsid complexes with the intact VP30 $C$-terminal domain allow to be transported to the site of assembly and incorporated into VLPs (Hartlieb et al., 2007).

At catalytic concentrations, VP30 activates Ebolavirus transcription. In contrast, transcription activity is suppressed with increasing VP30 concentration. Therefore, an equilibrium between activating and non-activating forms of VP30 might regulate Ebolavirus transcription activity and may control the balance of tran- 


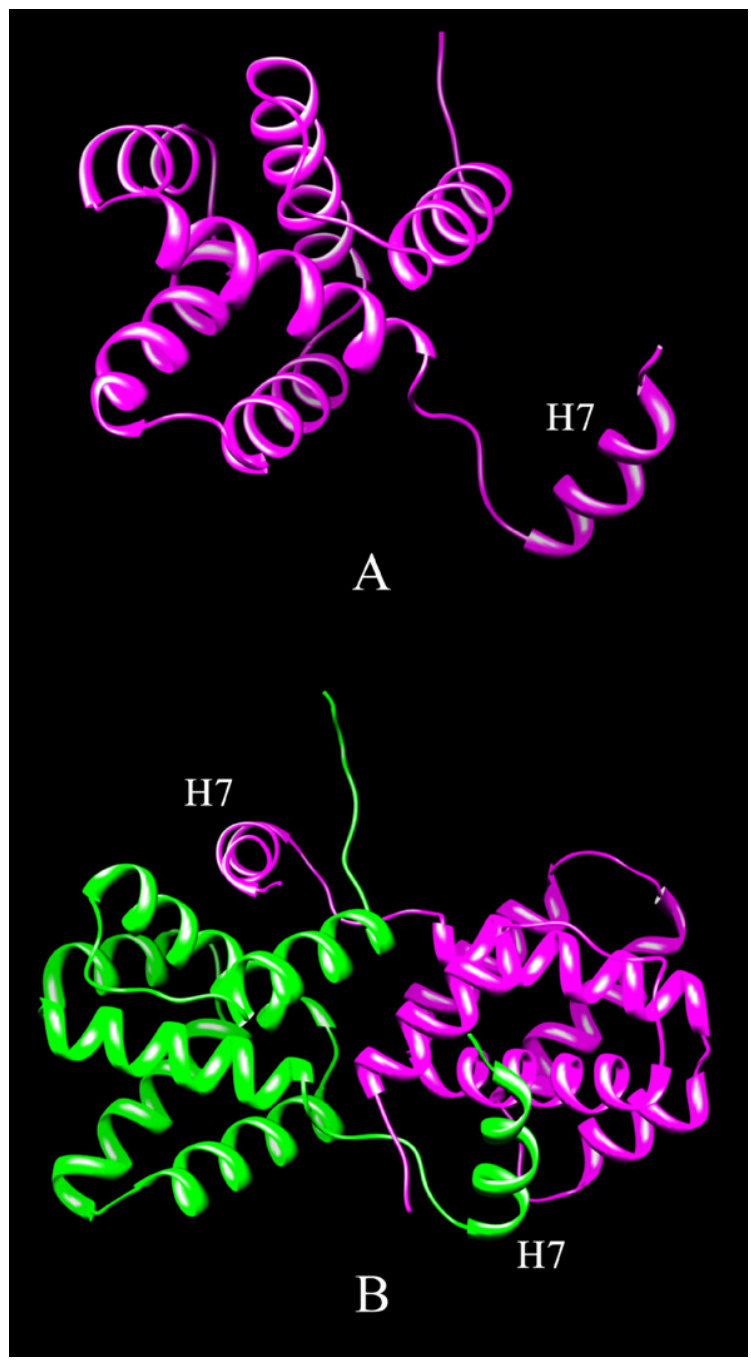

Fig. 6. Zaire ebolavirus VP30 protein structure. (Panel A) Ribbon diagram of the $C$-terminal domain of the VP30 monomer shown in magenta (PDB ID: 2I8B; Hartlieb et al., 2007). (Panel B) Ribbon diagram of the $C$-terminal domain of the VP30 dimer shown in magenta and green (PDB ID: 2I8B; Hartlieb et al., 2007). H7 indicates the $\alpha$-helix 7. Molecular graphics images were produced using the UCSF Chimera package (Pettersen et al., 2004). (For interpretation of the references to colour in this figure legend, the reader is referred to the web version of this article.)

scription and replication. Furthermore, phosphorylation of VP30 (which takes place essentially at Ser residues present in the Ser29-Ser46 region and at Thr52) regulates negatively transcription activation. However, it facilitate VP30 binding to NP inclusions (see Mühlberger et al., 1999; Modrof et al., 2002; Hartlieb et al., 2007).

Because of its essential function in viral transcription, VP30 is a potential candidate for antiviral therapy. Dimerization of the VP30 $C$-terminal domain generates a $7 \times 11 \AA$ wide cavity whose interior is lined by hydrophobic residues and its opening by conserved hydrophilic residues. Targeting this site by a small molecule might inhibit transcription activation and thus productive infection of target cells. Furthermore, the oligomerization of VP30 is inhibited by the 25-mer peptide (E30pep-wt) derived from the Ebolavirus VP30 amino acid sequence Gln91-Glu113 representing the homooligomerization domain. Thus, E30pep-wt seems to bind efficiently to VP30 blocking both the protein homooligomerization and the viral replication. This suggests that the inhibition of VP30 oligomerization may represent a target for Ebolavirus antiviral drugs (see Hartlieb et al., 2003, 2007). 
The ability of VP30 to activate and modulate transcription is independent of its ability to bind to the nucleocapsid complex by interaction with NP. Interestingly, zinc binding to VP30 (showing a unconventional zinc-binding $\mathrm{Cys}_{3}$-His motif comprising Pro68-Leu95 amino acids) modulates viral transcription without influencing the association to nucleocapsid-like particles (see Modrof et al., 2003; Hartlieb et al., 2007).

Lastly, VP30 is capable of eliciting protective immune responses to Zaire ebolavirus indicating that it may be an important component of a vaccine designed to protect humans from Ebola haemorrhagic fever (Wilson et al., 2001).

\subsection{VP24 protein}

Ebolavirus VP40 is the primary matrix protein and the most abundant virion component. Although several functions have been attributed to the Ebolavirus VP24, its precise role in viral replication remains ambiguous and somewhat controversial. The VP24 was postulated to be a 'minor matrix protein' and a minor component of virions or to function in viral uncoating. Moreover, VP24 appears to be essential for the formation of a functional ribonucleoprotein complex. VP24 possesses structural features commonly associated with viral matrix proteins and may have a role in virus assembly and budding. Lastly, the expression of VP24 results in the inhibition of IFN-induced gene expression and in the inhability of IFNs to induce an antiviral state (see Han et al., 2003; Jasenosky and Kawaoka, 2004; Licata et al., 2004; Hoenen et al., 2006b; Reid et al., 2006; Watanabe et al., 2006).

\subsection{L protein}

The non-segmented negative-strand RNA viruses include some of the most problematic human, animal, and plant pathogens (e.g., Ebolaviruses and Marburgvirus) (see Barr et al., 2002). Ebolavirus and Marburgvirus gene transcription is catalyzed by protein L, a RNA-dependent RNA polymerase (Volchkov et al., 1999). Sequence comparison of the Ebolavirus L proteins with several corresponding proteins of other non-segmented, negative-strand RNA viruses, including Marburgvirus, indicates a close relationship between filoviruses and members of the Paramyxovirinae (Volchkov et al., 1999). A combination of sequence similarity and threading analysis suggests that the $2^{\prime}$ - $O$-ribose methyltransferase domain is involved in capping of the viral mRNAs (Ferron et al., 2002). The key feature of transcriptional control in the non-segmented negative-strand RNA viruses is polymerase entry at a single $3^{\prime}$-proximal site followed by obligatory sequential transcription of the linear array of genes. The levels of gene expression are primarily regulated by their position on the genome. In addition, non-segmented negative-strand RNA virus gene expression is regulated by $c i s$-acting sequences that reside at the beginning and end of each gene and the intergenic junctions (Barr et al., 2002).

All known eukaryotic and some viral mRNA capping enzymes transfer a GMP moiety of GTP to the 5'diphosphate end of the acceptor RNA via a covalent enzyme-GMP intermediate to generate the cap structure. In contrast, protein L appears to incorporate the GDP moiety of GTP into the cap structure of transcribing mRNAs. As reported for Vesicular stomatitis virus (VSV), the Ebolavirus RNA-dependent RNA polymerase (L protein) may catalyze the capping reaction by an RNA-GDP polyribonucleotidyltransferase activity, in which a 5'-monophosphorylated viral mRNA-start sequence is transferred to GDP generated from GTP via a covalent enzyme-RNA intermediate (Ogino and Banerjee, 2007).

\section{Virus assembly and budding}

Negative-strand RNA virus particles are formed by a process that includes the assembly of viral components at the plasma membranes of infected cells and the release of particles by budding (see Jasenosky and Kawaoka, 2004; Morita and Sundquist, 2004; Schmitt and Lamb, 2004; Hartlieb and Weissenhorn, 2006; Watanabe et al., 2006).

Although all the structural information to build a viral particle is encoded in the viral genome, filoviruses (like other enveloped viruses such as HIV-1) hijack cellular protein machines to mediate assembly and bud- 
ding from cellular membranes. The recruitment of cellular factors serves potentially two major purposes. Firstly, it needs to recruit factors that help to initiate the assembly process mediated by the matrix protein. Secondly, recruitment of endosomal sorting complexes required for transport may be required for the last step of the budding process, the release of the fully assembled virus particle from cellular membranes. Therefore, selective employment of cellular proteins by enveloped viruses may provide specialized fine tuning accessories for virus assembly and release (see Jasenosky and Kawaoka, 2004; Morita and Sundquist, 2004; Schmitt and Lamb, 2004; Hartlieb and Weissenhorn, 2006; Watanabe et al., 2006).

Viral sequence motifs that are absolutely required for budding have been identified over the last decade, they are termed late domains since affect a late step in budding. A number of late domain sequences have been described to function in both positive- and negative-strand RNA virus assembly and budding. The late domains serve as entry points into a network of proteins that normally functions in multi-vesicular body (MVB) biogenesis. The protein network involved in MVB formation is implicated in membrane protein trafficking from the Golgi and plasma membranes via the endosomal system to the lysosome for degradation (see Martin-Serrano et al., 2004; Morita and Sundquist, 2004; Schmitt and Lamb, 2004; Hartlieb and Weissenhorn, 2006; Watanabe et al., 2006).

VP40 buds from the cell surface forming VLPs. Ebolavirus VP40 contains two overlapping late domains ProThrAlaProProGluTyr while Marburgvirus VP40 contains only the putative functional ProProProTyr motif. Ebolavirus VP40 was shown to interact with Tsg101 via its ProThrAlaPro motif in vivo and in vitro with both monomeric and oligomeric VP40; Tsg101 binds also ubiquitin (see Neumann et al., 2005; Johnson et al., 2006a,b; Hartlieb and Weissenhorn, 2006).

The VP40 ProProProTyr motif mediates interactions with proteins that contain TrpTrp domains, such as ubiquitin ligases. The ProProGluTyr motif was shown to interact with TrpTrp domain 3 of human Nedd4 in vitro, which requires the oligomeric ring-like conformation of $\mathrm{VP} 40$. The TyrPro $(\mathrm{X})_{n}$ Leu motif mediates binding to protein ALIX/AIP1 that itself interacts with Tsg101 (see Fisher et al., 2007). It was long speculated that ubiquitin plays a role in assembly and budding since ubiquitin is incorporated into retroviral particles (see Harty et al., 2000; Noda et al., 2002; Licata et al., 2003; Panchal et al., 2003; Gruenberg and Stenmark, 2004; Morita and Sundquist, 2004; Jasenosky and Kawaoka, 2004; Schmitt and Lamb, 2004; Bieniasz, 2006; Hartlieb and Weissenhorn, 2006; Watanabe et al., 2006; Urata et al., 2007).

The presence of intact late domains is required for the efficient release of VP40-containing VLPs albeit some VP40 release takes place in the absence of late. Furthermore, Ebolavirus VP40 late domains are not required for virion production in cell culture. This poses the question as to whether yet other unknown sequences in VP40 are implicated in the assembly and budding process (see Hartlieb and Weissenhorn, 2006).

VP40 reveals mostly plasma membrane targeting, including lipid raft microdomain localization. Furthermore, VP40 interacts with nucleocapsid structures and endosomal membranes in Ebolavirus- and Marburgvirus-infected cells. This suggests that VP40 is transported through the retrograde late endosomal pathway en route from the endosome to the plasma membrane (see Jasenosky et al., 2001; Hartlieb and Weissenhorn, 2006).

The envelope of filoviruses is decorated by the trimeric surface protein GP, a type I TM protein, which mediates cell entry (see Schibli and Weissenhorn, 2004). Two $C$-terminal acetylated-Cys residues (between the TM region and the short cytoplasmic region) may play a role in a postulated interaction with the matrix protein VP40 (see Hartlieb and Weissenhorn, 2006). Note that in Marburg virus-infected cells, GP localizes to MVBs, which are enriched in VP40. This suggests that GP and VP40 are transported together to the site of budding at the plasma membrane. In addition, such a co-localization is also consistent with virus budding into endosomal structures (see Kolesnikova et al., 2004a,b). Like VP40, GP is targeted to lipid raft microdomains in the plasma membrane. The co-expression of VP40 and GP supports and enhances the efficiency of VP40and GP-containing VLP formation, which is morphologically indistinguishable from infectious Ebola virus (see Jasenosky et al., 2001; Bavari et al., 2002; Noda et al., 2002). Interestingly, VLP-containing VP40 and GP have been shown to provide protection from filovirus infection upon VLP immunization (see Warfield et al., 2004).

Expression of NP, the major determinant of the nucleocapsid (see Huang et al., 2002; Licata et al., 2004; Noda et al., 2005, 2007), in mammalian cells leads to the formation of intracellular inclusion bodies, which are similar to those detected in Ebolavirus- and Marburgvirus-infected cells (see Noda et al., 2005). NP enhances 
budding activity of VP40 suggesting an NP-VP40 interaction (Licata et al., 2004). Although VP40 interacts with NP-containing nucleocapsids, VP40 and NP do not co-localize in MVBs, indicating that different forms or conformations of VP40 pass by the MVB pathway and associate with nucleocpasids (Kolesnikova et al., 2004a,b). Although it is currently not known how the assembled nucleocapsids leave the site of inclusion bodies, it might involve the cellular cytoskeleton and VP40 interactions with microtubules (Ruthel et al., 2005). Furthermore, NP is highly phosphorylated at its $C$-terminus, which might play a role in regulating either RNA-protein or protein-protein interactions (see Licata et al., 2004; Noda et al., 2007). Not only NP, but also VP35 is packaged within VP40 VLPs (see Licata et al., 2004; Hartlieb and Weissenhorn, 2006; Johnson et al., 2006a,b).

Although VP24 is implicated in the nucleocapsid assembly (see Huang et al., 2002; Han et al., 2003; Jasenosky and Kawaoka, 2004; Licata et al., 2004; Hoenen et al., 2006b; Reid et al., 2006; Watanabe et al., 2006), it might be either important for the assembly of transport competent nucleocapsids or the association of nucleocapsids with the transport machinery or in the targeting of the nucleocapsids to the budding sites containing GP and VP40 (Bamberg et al., 2005; Kolesnikova et al., 2004b).

Very recently, the influence of calcium/calmodulin on budding of Ebola VLPs has been reported. The mechanism of calcium/calmodulin-mediated inhibition of Ebola VLP budding may involve the Ras/Raf/ MEK/ERK signaling pathway (Han and Harty, 2007).

As a whole: $(i)$ the transport of the matrix protein VP40 to the plasma membrane occurs by the retrograde late endosomal pathway via MVBs. Then, VP40 re-localizes the cellular budding machinery to the site of virus assembly and budding. VP40 was also found in association with viral inclusions containing assembled nucleocapsids, probably in a conformation different from the monomeric form such as the hexameric form or the octamers in complex with RNA. (ii) GP expression follows the regular secretory pathway and localizes to the late endosome, after proteolytic cleavage in the trans-Golgi network, and accumulates in MVBs together with VP40. Both are thus co-transported to the site of assembly and budding. (iii) NP-RNA interactions are sufficient for nucleocapsid assembly that recruits VP30, VP35, and L. Nucleocapsids accumulate in cellular inclusions that co-localize with small amounts of VP40. These complexes are then transported to VP40-and GPcontaining MVBs and to the plasma membrane that leads to virus particle assembly and release (Fig. 7) (Hartlieb and Weissenhorn, 2006).

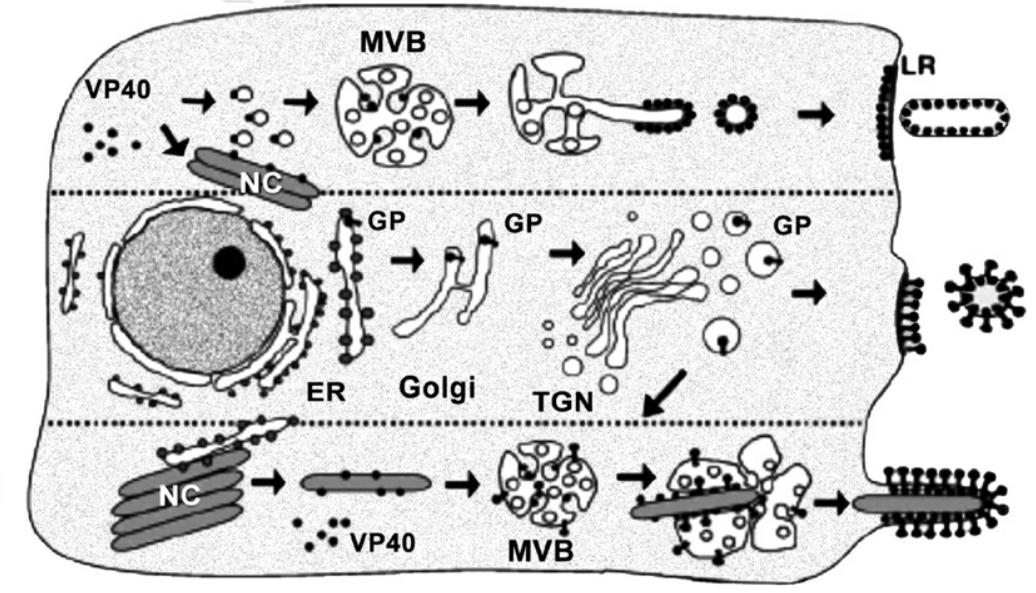

Fig. 7. Schematic illustration of distinct transport pathways of viral components to the site of assembly and budding. (Panel A) Transport of VP40 along the retrograde late endosomal pathway. (Panel B) Transport of the glycoprotein GP along the regular secretory pathway. (Panel C) Transport of nucleocapsids (NC) and assembly of viral particles containing NC, VP40, and GP. Both GP and VP40 are targeted to lipid raft microdomains (LR) that serve as platforms for assembly. GP and VP40 expression induces either the release of GP containing vescicles or VP40 containing filamentous VLPs (Panels B and C, respectively). ER, endoplasmic reticulum; MVB, multi-vesicular body. TGN, trans-Golgi network. The figure was modified from Kolesnikova and Becker (2004). 


\section{Filovirus infection}

\subsection{Epidemiology}

Marburgvirus is named after the town in Germany where the first cases of filovirus infection were recognised, and a filovirus first isolated, in 1967 (Table 1) (Siegert et al., 1967), when simultaneous outbreaks of an acute severe haemorrhagic illness occurred in Marburg, Frankfurt, and Belgrade. The illness affected animal handlers and laboratory workers in three vaccine production facilities who had been exposed to blood, organs or cell cultures from green (vervet) monkeys (Cercopithecus aethiops) imported from Uganda. Twenty-five human primary cases (of whom seven died) were identified; a further case was later identified by retrospective serology (Feldmann et al., 1996). There were six secondary cases; all had provided direct patient care to a primary case. These included two junior doctors, who had needlestick injuries after taking blood; a morgue attendant; a nurse, and the spouses of two of the patients, one of whom had contact with 'soiled linen' while caring for her partner, a vet who had autopsied five of the monkeys, and the other from whose partner Marburgvirus was isolated from semen (see Martini et al., 1968; Martini, 1969; Stille et al., 1 1968; Todorovitch et al., 1971; Hennessen et al., 1971).

In 1976, concurrent outbreaks of haemorrhagic fever occurred in Yambuku, northeastern Zaire (now Democratic Republic of Congo), and in Nazara, Maridi and the surrounding areas in southern Sudan. Around 300 cases were identified in each outbreak; case fatality rates exceeded 50\% (53\% in Sudan, 88\% in Zaire) (WHO, 1978a,b). In both Maridi and Yambuku, transmission was amplified within hospitals, through provision of patient care without personal protective equipment, and, in the hospital in Yambuku, where most medicines were given by injection, by the reuse of needles and syringes. The new filovirus isolated from samples from patients in Zaire was named after the river Ebola, which runs through the area where the outbreak occurred (Johnson et al., 1977). Later work showed that although the outbreaks overlapped in time, and population movement between the two areas was common, the outbreaks had been caused by two antigenically distinct types of Ebolavirus, Zaire ebolavirus and Sudan ebolavirus (Bowen et al., 1980; Richmond et al., 1983).

Reston ebolavirus was discovered in 1989, causing haemorrhagic fever in cynomolgus macaques (Macaca fascicularis) exported from the Philippines, and held in primate quarantine centres in Virginia, Texas, and Pennsylvania (CDCP, 1989, 1990; Jahrling et al., 1990). Seroconversion was documented in four animal handlers (including one who cut himself while performing an autopsy on an infected animal), but was not associated with any clinical illness (CDCP, 1990). Further introductions of the virus, all traced to the same export breeding facility in Luzon, occurred in 1990 (USA), 1992 (Italy), and 1996 (USA) (WHO, 1992; CDCP, 1996; Rollin et al., 1999; Miranda et al., 1999). The original source of infection has not been discovered. Reston ebolavirus does not seem to cause haemorrhagic illness in humans, though the infection can be lethal for nonhuman primates (CDCP, 1996; Takada and Kawaoka, 2001; Mahanty and Bray, 2004).

The fourth species of Ebolavirus, Ivory Coast ebolavirus, has been isolated from a human only once, in 1994, from a scientist who was repatriated to Switzerland after developing a severe acute illness, with fever and rash, unresponsive to antimalarial drugs, but without haemorrhagic signs, a few days after performing an autopsy on a wild chimpanzee from the Tai National Park that had died from a haemorrhagic illness (Formenty et al., 1999). The virus was also identified in fixed tissue from the chimpanzee (Le Guenno et al., 1995).

Between 1967 and 1994 only seven cases of Marburg haemorrhagic fever (three sporadic cases in expatriate travellers in rural Africa, associated with an additional three secondary cases, and a laboratory acquired infection in Russia) (Gear et al., 1975; Smith et al., 1982; Nikiforov et al., 1994; Johnson et al., 1996) and four Ebola haemorrhagic fever incidents (Heymann et al., 1980; Le Guenno et al., 1999; Baron et al., 1983; Georges et al., 1999) were reported. Then, in 1995, a hospital-amplified outbreak of Zaire ebolavirus occurred in Kikwit in the Democratic Republic of Congo (formerly Zaire) (Khan et al., 1999). The outbreak had smouldered for four months, misdiagnosed clinically as bacterial dysentery, and attracted the attention of the national authorities only after the deaths of a cluster of health care workers infected while assisting, largely unprotected from exposure, at the laparotomies performed on an infected laboratory technician thought to have an acute surgical abdomen. The Kikwit outbreak attracted intense, and unexpected, media attention, and lessons learned from the outbreak led to a reorganization of the international response to infectious disease emergencies (Hey- 
mann et al., 1999). In the last five years, nine outbreaks of filovirus infection have occurred in Uganda, Gabon, Republic of the Congo, Democratic Republic of Congo, and Sudan (Arthur, 2002; Pourrut et al., 2005; http:// www.who.int/csr/don/2004_08_07/en/index.html). These include the largest Ebolavirus outbreak yet recorded (425 cases, 83\% mortality), centered on Gulu in Uganda in 2000-2001, where initial cases again passed undetected and transmission was amplified within hospitals (WHO, 2001; Okware et al., 2002), the Marburgvirus outbreak around Durba in northeastern Democratic Republic of Congo in 1998-2000, where many of the cases were young men who worked in the local gold mine (the main source of paid employment), and the overall case-fatality rate was 83\% (128/154) (WHO, 1999; Bausch et al., 2003), and the 2004-2005 outbreak of Marburgvirus infection in Uige province in Angola (374 cases, $88 \%$ mortality), where transmission was amplified by unsafe injections in health care centres, private clinics, and in self-treatment at home (Ndayimirije and Kindhauser, 2005; Peters, 2005; http://www.who.int/csr/don/2005_08_24/en/index.html).

Human filovirus infections are generally regarded as zoonoses, although their natural reservoirs remain unknown and, in the case of Sudan ebolavirus, a link with an animal species has not been clearly established. Postulated reservoirs have included plants, arthropods, reptiles, small mammals (e.g., bats and rodents) (Pourrut et al., 2005); ecological niche modelling, based on the geographical distribution of reported human filovirus infections, is now being used to identify candidate taxa for priority investigation (Peterson et al., 2004a,b). The recent outbreaks of Zaire ebolavirus in Gabon and the Republic of the Congo have been linked, epidemiologically and virologically, with an epizootic in great apes and other animals that has led to a rapid decline in gorilla and chimpanzee populations, and damaged a developing eco-tourism industry (Leroy et al., 2004; Pourrut et al., 2005). The epizootic may be progressing geographically, moving gradually through animal populations, from Gabon into the Republic of the Congo. Genetic sequencing points to multiple introductions of virus from an as yet unidentified reservoir. Surveillance of animal deaths has been used, with limited success, to provide an early warning system for human outbreaks (Pourrut et al., 2005; Rouquet et al., 2005), and attempts have been made to educate communities about the dangers of contact with, and consumption of 'found' animal carcasses (http://www.who.int/csr/disease/ebola/ebolacongofr.pdf). These have been the apparent source of infection in several outbreaks, including those in Gabon in 1996 (when 18 children who had helped to butcher and carry home the carcass of a dead chimpanzee that they had found in the forest developed Ebola haemorrhagic fever), and in Gabon and the Republic of the Congo between 2001 and 2005, when index cases had handled gorillas, chimpanzees, or duiker (forest antelope), or their carcasses (http://www.who.int/csr/disease/ebola/ebolacongofr.pdf). Animal to human transmission is assumed to have followed the exposure of non-intact skin, or mucous membranes, to animal blood containing infective virus. It is not known whether transmission can follow consumption of infected meat, though it might be expected that the transmission risk from exposure to adequately cooked meat alone would be low (http://www.who.int/csr/ disease/ebola/ebolacongofr.pdf).

\subsection{Pathogenesis}

All filovirus infection of human and non-human primates are characterized by a similar illness that differs only in severity and fatality rate. Existing data on the pathological mechanism involved in the disease have been obtained by experimental infection of non-human primates and rodents as well as by clinical and laboratory observation collected during the human outbreaks. The main pathogenic mechanism involved are: the suppression of innate and adaptive immune response, the infection followed by death of a large number of cells from a broad range of tissue, a strong inflammatory response, and the triggering of coagulopathy (see Mahanty and Bray, 2004; Fisher-Hoch, 2005; Mohamadzadeh et al., 2007).

Filoviruses can infect and kill a large number of different cell types. This apparent lack of target specificity is due to the wide distribution of cell-surface lectins that are involved in the binding of the viral surface GP. The cell destruction due to the viral infection could result from the viral shut-down of several cellular process as well as from the toxic effect of glycoproteins and other structural or matrix viral proteins. Moreover, Filovirus can affect immune system by a multiplicity of mechanisms. The interaction between viral and host proteins can suppress certain innate antiviral responses. Ebolavirus VP35, in particular, has showed in several cellular models the capacity to reduce IFN- $\alpha$ production by infected cells (Basler et al., 2000; Gupta et al., 2001; Basler et al., 2003; Bosio et al., 2003). However, discordant findings have been reported by other authors 
that observed a large production in infected human macrophages, and high blood concentrations, in nonhuman primates, of IFN- $\alpha$ (Hensley et al., 2002).

Macrophages, monocytes, and dendritic cells are early targets of viral infection. Infected macrophages cannot restrict viral replication and produce proinflammatory cytokines, chemokines, and tissue factors. These soluble products can attract additional target cells, induce vasodilatation, increase vascular permeability and trigger disseminated intravascular coagulation. Infected dendritic cells also secreted proinflammatory mediators and are impaired in their activity of antigen presenting cells. In addition, massive 'bystander' apoptosis of natural killer and $\mathrm{T}$ cells has been observed in non-human primates and mice models (Bray and Geisbert, 2005). Indirect evidences that a similar effect occurs also in human beings have been obtained in study carried out during a human outbreak, where markers of intravascular apoptosis have been detected in blood samples from fatally infected patients but not from survivors (Baize et al., 2000).

Regarding the major mechanisms that underlie the typical vessel damage and coagulation disorder, infection of endothelial cells has been well documented in non-human primates, but is observed only one day after the onset of disseminated intravascular coagulation and the endothelium remained relatively intact even at terminal stages of disease (Geisbert et al., 2003). In vitro cultured human endothelial cells are highly permissive to Ebolavirus replication but no significant cytopathic effects have been observed (Geisbert et al., 2003). These data suggest that, likewise other negative-strand RNA virus, haemorrhagic effects are likely triggered by immune-mediated mechanisms. It has been hypothesized that VPs too can directly participate in the induction of endothelial cells damage. In particular, VLPs consisting of Ebolavirus VP40, GP1, and GP2 were able to activate endothelial cells and induce a decrease in the barrier function. However, GP seems to posses an antiinflammatory role by inducing a recovery of endothelial barrier function (Wahl-Jensen et al., 2005).

\section{Clinical features and management}

Although genetically distinct, Marburgvirus and the Zaire, Sudan, and Ivory Coast species of Ebolavirus cause similar human illnesses. After an incubation period of 5-7 days (range 2-21 days; possibly shortened by high-inoculum exposure), there is an abrupt onset of non-specific prodromal symptoms: fever, headache, severe malaise, myalgia, nausea, and vomiting, abdominal pain and diarrhoea (often bloody), sometimes accompanied by signs of conjunctivitis or pharyngitis, or the development of a maculopapular rash towards the end of the first week. Early in the second week, the disease either worsens dramatically, with signs of vascular involvement and coagulopathy (ranging from mild ooze from venepuncture sites, easy bruising, gingival bleeding, and epistaxis, to catastrophic haemorrhage, often gastrointestinal), dehydration, shock, multi-organ failure, and death, or a slow recovery begins. Antiviral drugs are not effective, and management - maintenance of fluid and electrolyte balance, analgesia, oxygen therapy, transfusion, and treatment of coagulopathy with platelet and clotting factor concentrates and heparin - is wholly supportive. Co-existing infections (e.g., malaria) should be excluded, or, if this is not possible, treated presumptively using standard treatment regimes. The differential diagnosis includes shigellosis, typhoid, meningitis, other haemorrhagic fevers (including yellow fever), and non-infective causes of disseminated intravascular coagulation (see Martini et al., 1968; Baron et al., 1983; Bwaka et al., 1999; Formenty et al., 1999; Takada and Kawaoka, 2001; Mahanty and Bray, 2004; Fisher-Hoch, 2005).

Zaire ebolavirus has been viewed as the most virulent of the filoviruses for humans, and Marburgvirus the least virulent, but our understanding of filovirus virulence has been challenged by the recent outbreaks of Marburgvirus in Democratic Republic of Congo and Angola, where mortality of over $80 \%$ has been reported, comparable with that in outbreaks of Zaire ebolavirus in Yambuku (88\%) and Kikwit (81\%), higher than that reported in outbreaks of Zaire ebolavirus (59-78\%) in Gabon and Republic of the Congo, and more than three times that $(23 \%)$ in the European Marburgvirus outbreak in Europe. Some experts have suggested that the effects of filovirus infection, which incapacitate innate immune response mechanisms, are such that recovery would be unlikely even if intensive medical care were to be provided (Peters, 2005). However, in some outbreaks in Africa, survival rates have tended to improve towards the end of the outbreak (Colebunders et al., 2004; Guimard et al., 1999; Francesconi et al., 2003). It is not clear whether this is the result of the improved care (intravenous fluids, protein-rich feeding, transfusion, presumptive use of antimalarials, and antibiotics) made possible once the numbers affected fall and conditions become less chaotic; an artefact 
caused by variations in case ascertainment, or a viral 'passage' effect, whereby viral virulence lessens with successive generations of transmission. It is also now evident that asymptomatic infections can occur (Leroy et al., 2000). Perhaps mortality rates are not determined solely by viral factors, and other factors, which might include the effectiveness of rehydration, the patient nutritional status and haematological reserve, co-infection with other pathogens (e.g., malaria and HIV), and bacterial superinfection are more important determinants of survival than has been assumed. In this context, it is interesting that key social and economic indicators (http://www.wfp.org/Country_Brief/Hunger_Map/map), including the reported prevalence of undernutrition (Uganda, 5-19\%; Gabon, 5-19\%; Sudan, 20-34\%; Democratic Republic of Congo, Republic of the Congo, and Angola, all $>35 \%$ ) (http://www.unicef.org/sowc06/intro.html) to some extent parallel the differences in reported mortality rates in filovirus outbreaks in these countries.

Virological confirmation of the diagnosis (by antigen capture ELISA, RT-PCR for viral RNA, and specific IgG/IgM detection) (Ksiazek et al., 1992; Towner et al., 2004) requires the specialized expertise available only in tertiary care level laboratory facilities. It therefore almost inevitably requires international referral of specimens from initial cases, which may be challenging, as filovirus infections have tended to occur in remote areas, often affected by conflict, where fuel shortages are common, transport links poor or absent, and where healthcare facilities lack capacity even for the diagnosis of the most common infection, malaria. The networks put in place for the global polio eradication program to ensure the rapid transport of specimens (http:// www.polioeradication.org) with maintenance of the reverse-cold chain, could, if sustainable, be used to improve access to diagnostic testing. Once an outbreak has been confirmed, and external assistance provided, mobile field laboratories can be deployed and used to provide rapid, on-site, virological confirmation, which can be used to guide decisions about case management and isolation, and follow up of contacts. Progress has also been made in developing techniques for testing specimens other than blood or serum, including oral fluid samples and post-mortem skin snips (Zaki et al., 1999), which are less dangerous than blood to collect, to transport, and to examine.

Cases are viraemic from the onset of symptoms, and become progressively more viraemic as disease progresses; early onset of high-level viraemia carries a poor prognosis (Towner et al., 2004). Person to person transmission follows percutaneous (e.g., needlestick injury and unsafe injection) or mucocutaneous (exposure of the eyes, nose or mouth) exposure, or exposure of non-intact skin to infected blood or body fluids (vomit, feces, and urine), and therefore occurs most often in the context of providing care for a case, either in a healthcare setting or in the home, or when preparing the body for burial. Sexual transmission, during convalescence, has been reported, but there is no carrier state. Transmission by small particle aerosols has been demonstrated in animal models in the laboratory (Johnson et al., 1995), but there is no clear evidence that airborne spread from person to person occurs.

\section{Prevention and control}

Outbreak control and prevention is not complex, at least in theory. It requires recognition of the illness, early isolation of suspect cases, personal protective equipment (gloves, gowns, masks, and eye protection) to prevent exposure of healthcare workers and other careers to blood and body fluids, and the training to use it correctly, safe injections, effective follow up and management of contacts, human, safe, and culturally appropriate burial of the dead, and community education and involvement, harnessing, when possible, existing local understandings of disease transmission and prevention. When these measures have been applied, outbreaks of filovirus infection have usually been rapidly controlled (see Hewlett and Amola, 2003).

In practice, however, outbreak recognition is usually delayed, such that index cases are usually identified retrospectively, unless cases recur at, or close to, the site of a previous outbreak. Reporting is hampered by lack of training in surveillance and diagnosis, by poor communications systems and underfunding. The contact of cases with the health care system is as likely to result in the amplification of the outbreak as in control of transmission. Healthcare workers and other careers become infected because the personal protective equipment and supplies of disinfectants taken for granted in well-resourced countries are often simply not available; indeed, health centres may have to function without running water, electricity, or safe waste-disposal systems, and with unpaid staff. An explosive increase in the number of cases can follow exposures through unsafe injections. Disposable needles and syringes, which cannot be sterilized effectively, are more likely to be re-used 
when supply is limited; a syringe may be filled with a drug and used to dispense injections to multiple patients, or a vial of a drug intended for single-dose adult use used to treat multiple pediatric patients. Such practices remain widespread, despite the recognition that they are also associated with transmission of hepatitis $\mathrm{C}$, hepatitis B, and HIV (Kane et al., 1999). The perception that treatments given by injection are more powerful than those which are not may have contributed to transmission of Marburgvirus in Angola, where home injections are so frequent that community campaigns targeted at reducing this practice are needed to control the epidemic. Outbreaks of filovirus infections, and transmission of other bloodborne virus infections will continue to occur, and may, as demand for 'western-style' health care continues to grow, become more frequent, unless health authorities at local, national and international level are prepared to pay more than lip service to the precept that medicine should first do no harm, and invest in the effective implementation of injection safety and infection control programs in public, private, and informal care settings (see Fisher-Hoch, 2005).

\section{Filovirus therapy}

There are few reports of treatment of human filovirus cases. Although convalescent serum from surviving patients, extracorporeal blood treatment with haemosorbents and dialysis, equine anti-Ebola immunoglobulin, and IFN have been used to treat human filovirus cases, their efficacy has never been convincingly demonstrated (see Bray and Paragas, 2002; Bray and Pilch, 2006).

A number of steps in the filovirus replication pathway offer targets for antiviral therapy, such as blockade of the virus receptor, prevention of membrane fusion, interference with genome transcription and replication, inhibition of cellular enzymes (e.g., $S$-adenosylhomocysteine hydrolase), enhancement of innate antiviral mechanisms, interference with viral maturation, assembly, budding, and release, modulation of the clinical syndrome, and treatment with antiviral agents (see Bray and Paragas, 2002; Bray and Pilch, 2006).

Two distinct situations must be considered in developing specific treatments for filovirus infections. The first is the need for post-exposure prophylaxis to deal with the accidental infection of a laboratory investigator or of a health care worker during an outbreak. In such cases, the goal of therapy would be either to prevent viral replication and dissemination or else to significantly slow its pace, providing time for antigen-specific immune responses to mobilize and suppress the virus. The most experience in experimental animals has been obtained with antibody therapy (e.g., anti-GP). IFN- $\alpha$ forms in use for the treatment of hepatitis C may also be of value in retarding filovirus dissemination, IFN-inducers might also be of some benefit. $S$-adenosylhomocysteine hydrolase inhibitors have received only limited clinical evaluation because of problems with toxicity. The second situation concerns the treatment of patients who have progressed to symptomatic illness, this is a far more daunting problem. Therapy for such cases is needed in order to reduce mortality in filovirus outbreaks, but in practice it will be very difficult to evaluate any experimental form of treatment under the conditions of an epidemic in Africa. Only a combination of agents with differing mechanisms of action, implemented as quickly as possible after diagnosis, may be capable of reducing the mortality rate in a filovirus outbreak (see Bray and Paragas, 2002; Hensley et al., 2005; Bray and Pilch, 2006). Lastly, filovirus epidemics can be halted by isolating patients and instituting standard infection control and barrier nursing procedures (see Jeffs, 2006) (See Table 4).

\section{Filovirus vaccine}

Since the occurrence of the first Marburgvirus and Ebolavirus outbreaks numerous attempt to develop an effective vaccine has been made, however no licensed vaccines to prevent or treat this infection is currently available. Nevertheless several vaccine candidates have been tested for their ability to protect against filovirus challenge, with varying degree of success. As shown in Table 5, several viral preparations or proteins have been investigated for their immunological potential in rodents and non-human primate models by using both classical-, subunit-, DNA- and vector-based vaccination strategies (see Reed and Mohamadzadeh, 2007).

About classical vaccination strategies, complete protection in rodents was obtained by using ${ }^{60} \mathrm{Co}$-irradiated but not formalin-inactivated Marburgvirus; inactivated whole virus preparation of Ebolavirus showed only partial protection (see Hevey et al., 2001; Geisbert et al., 2002; Reed and Mohamadzadeh, 2007). The same authors reported that rodents vaccinated with an attenuated Marburgvirus were partially protected 
Table 4

Reported cases and outbreaks of human filovirus infection, 1967-2005

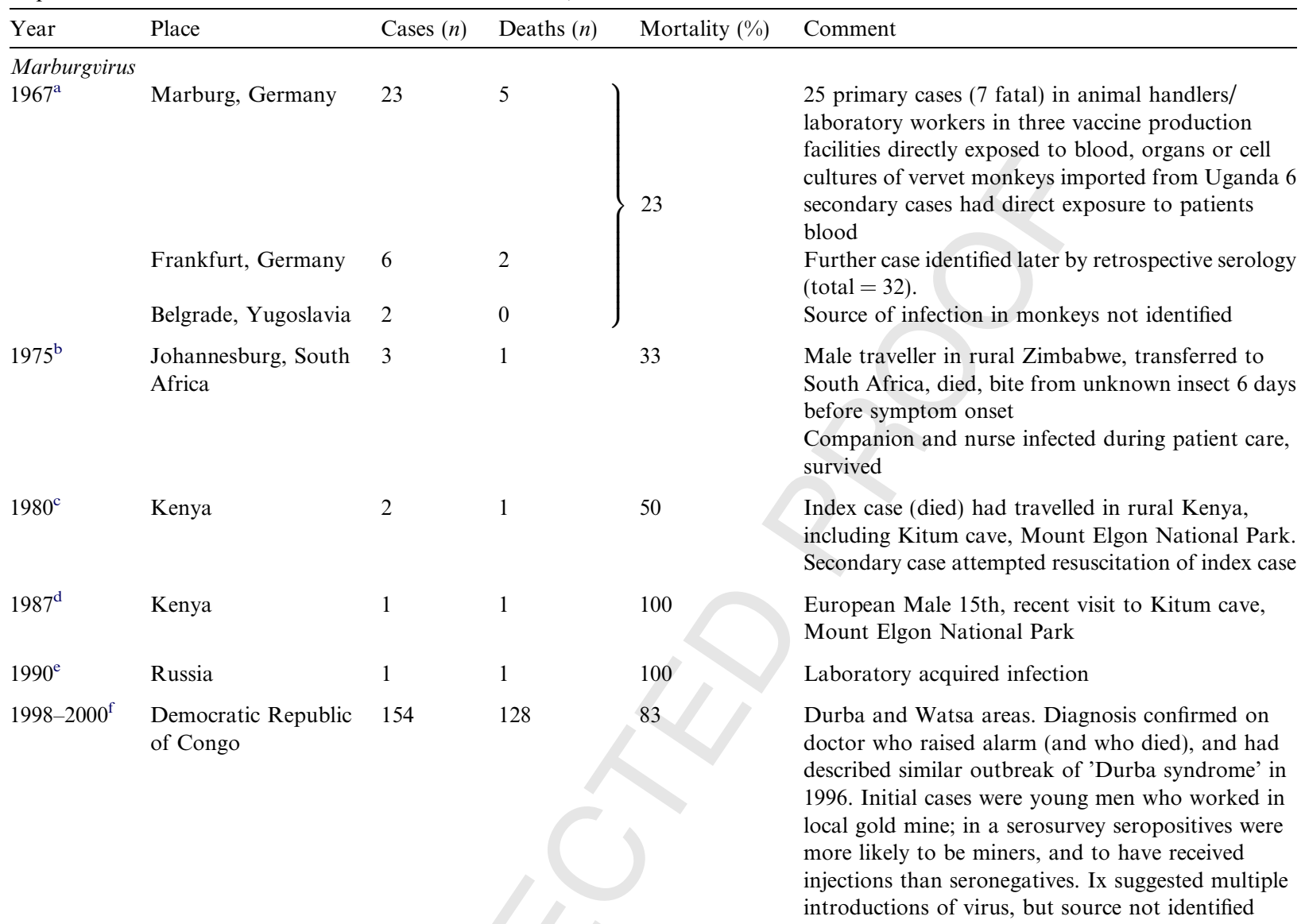

2004-2005 $\quad$ Angola

Zaire ebolavirus

$\begin{array}{ll}1976^{\mathrm{h}} & \text { Zaire (now } \\ & \begin{array}{l}\text { Democratic Republic } \\ \text { of Congo) }\end{array}\end{array}$
of Congo)

\section{Zaire (now}

Democratic Republic of Congo)
$1 \quad 1$
49

Gabon
29
Uige. Outbreak amplified by unsafe injections at home, in hospital/private clinics, and by indigenous healers

First recognised case had travelled in forest, purchased fresh antelope and.monkey meat, fever 4 days later treated with chloroquine injection in in Yambuku, haemorrhagic signs 10 days after this. Transmission in epicentre in Yambuku amplified by reuse of needles and syringes in hospital and and outpatient clinic, 11 of 17 medical staff died, outbreak ended soon after hospital was closed

Fatal haemorrhagic illness in Female 9th, in Tandala diagnosed retrospectively by serology

First cases in three temporary gold-panning camps (Mekouka, Minkebe, Andock) in deep rain forest; anecdotal, but unconfirmed, reports of dead gorillas, chimpanzees; later cases associated with hospital treatment, traditional healing or caring for sick 
Table 4 (continued)

\begin{tabular}{lllll}
\hline Year & Place & Cases $(n)$ & Deaths $(n)$ & Mortality $(\%)$ \\
\hline $1995^{\mathrm{k}}$ & $\begin{array}{l}\text { Democratic Republic } \\
\text { of Congo }\end{array}$ & 315 & 255 & 81
\end{tabular}

$1996^{\mathrm{i}}$

Gabon

31

21

68

1996-1997 Gabon

60

45

75

2001-2002 $\quad$ Gabon and Republic

124

97

78 of the Congo
143

Congo

$2003^{\mathrm{m}}$

$2005^{\mathrm{n}}$

Republic of the Congo

Sudan ebolavirus

$1976^{\circ} \quad$ Sudan

\section{7}

90

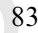

75

41
Comment

Centred on Kikwit. Index case charcoal burner working in forest adjoining the city. Amplification in two hospitals in the city; $25 \%$ cases healthcare workers. Source of infection not identified. Initially, cases diagnosed as dysentery

18 primary cases were children in Mayibout II who had helped to butcher or carry home dead chimpanzee found in forest; secondary cases followed in family members and in Mayibout I and Mvadi villages

Booue. Index cases were hunters living in logging camps in forest, one visited traditional healer, was scarified, healer and some patients infected, disease spread to Libreville, Lastourville and Johannesburg. Viral antigen detected in chimpanzee

Series of smaller outbreaks in border areas of Gabon and Republic of Congo. Disease spread from index cases in Mendemba (hunters who handled duiker [antelope] carcass) to Mekambo and Makokou. Other transmission chains began in Ekata (duiker carcass), Olloba (gorilla carcass), Etakangaye (chimpanzee carcass), Grand-Etoumbi (gorilla carcass)

Initial cases in gold mining camp in Mvoula (spread to Mbomo) linked to handling duiker carcass, and in Yembelengoye, near Entsiami (spread to Kelle) to handling gorilla carcass. 13 cases lab confirmed

Mbomo and Mbandza; 16 cases lab confirmed. No animal source identified, though wild boar carcass handled

Etoumbi and Mbomo; 1 case lab confirmed, others epidemiologically linked, index case handled gorilla carcass

Nzara and Maridi areas; initial cases in workers in a cotton factory in Nzara, main centre of local employment.

Nzara and Maridi, ie same locality as 1976 outbreak, initial cases again in cotton factory in Nzara

Primary cases passed undetected, outbreak centred in Gulu, with spread through transfer of cases to Masindi and Mbarara. Amplified within hospitals by lack of infection control, and within community by case contact during home nursing and traditional burial rites. Over 5000 contacts followed up

Yambio, south Sudan (close to Nzara and Maridi). 13 cases laboratory confirmed; some cases initially thought to be EHF reclassified as measles after testing

(continued on next page) 
Table 4 (continued)

\begin{tabular}{|c|c|c|c|c|c|}
\hline Year & Place & Cases $(n)$ & Deaths $(n)$ & Mortality (\%) & Comment \\
\hline \multicolumn{6}{|c|}{ Reston ebolavirus } \\
\hline $1989^{\mathrm{s}}$ & $\begin{array}{l}\text { United States of } \\
\text { America }\end{array}$ & 4 & 0 & 0 & $\begin{array}{l}\text { Illness in cynomolgus macaques exported from } \\
\text { Philippines and held in quarantine centres in Virginia } \\
\text { (Reston), Texas (Alice) and Pennsylvania } \\
\text { (Philadelphia); } 4 \text { animal handlers seroconverted, but } \\
\text { had no clinical illness }\end{array}$ \\
\hline $1990^{\mathrm{s}}$ & $\begin{array}{l}\text { United States of } \\
\text { America }\end{array}$ & 0 & 0 & NA & $\begin{array}{l}\text { Reintroduction of virus to quarantine centres in } \\
\text { Virginia and Texas via macaques from same export } \\
\text { centre in Philippines }\end{array}$ \\
\hline $1992^{t}$ & Italy & 0 & 0 & NA & $\begin{array}{l}\text { Virus introduced to quarantine centre in Siena; } \\
\text { macaques from export centre in Philippines involved in } \\
\text { earlier incidents }\end{array}$ \\
\hline $1996^{\mathrm{u}}$ & $\begin{array}{l}\text { United States of } \\
\text { America }\end{array}$ & 0 & 0 & NA & $\begin{array}{l}\text { Virus again detected in quarantine centre in Texas; } \\
\text { source centre in Philippines depopulated, export licence } \\
\text { revoked }\end{array}$ \\
\hline \multicolumn{6}{|c|}{ Ivory coast ebolavirus } \\
\hline $1994^{\mathrm{v}}$ & Cote d'Ivoire & 1 & 0 & 0 & $\begin{array}{l}\text { Ethologist performed autopsy on freshly dead } \\
\text { chimpanzee in Tai National Park. Repatriated to } \\
\text { Switzerland, rash and thrombocytopaenia but no frank } \\
\text { haemorrhage, recovered. Virus identified in chimpanzee } \\
\text { tissue also }\end{array}$ \\
\hline \multicolumn{6}{|c|}{ Unspecific ebolavirus } \\
\hline $1996^{\mathrm{w}}$ & Russia & 1 & 1 & 100 & Laboratory acquired infection, Sergiyev Posad, Moscow \\
\hline $2004^{\mathrm{w}}$ & Russia & 1 & 1 & 100 & $\begin{array}{l}\text { Laboratory acquired infection after needlestick injury } \\
\text { while injecting guinea pig, Vector, Koltsovo, Siberia }\end{array}$ \\
\hline $2004^{w}$ & $\begin{array}{l}\text { United States of } \\
\text { America }\end{array}$ & 1 & 0 & 0 & $\begin{array}{l}\text { Needlestick injury while injecting mice with 'attenuated } \\
\text { virus' in Fort Detrick; asymptomatic infection }\end{array}$ \\
\hline
\end{tabular}

${ }^{a}$ From Siegert et al. (1967), Martini et al. (1968), Stille et al. (1968), Hennessen (1971), Todorovitch et al. (1971) and Feldmann et al. (1996).

b From Gear et al. (1975).

c From Smith et al. (1982)

d From Johnson et al. (1996).

e From Nikiforov et al. (1994).

${ }^{\mathrm{f}}$ From WHO (1999) and Bausch et al. (2003).

g From Ndayimirije and Kindhauser (2005), Peters (2005) and http://www.who.int/csr/don/2005_08_24/en/index.html.

${ }^{\text {h }}$ From Johnson et al. (1977), WHO (1978a,b), Bowen et al. (1980) and Richmond et al. (1983).

${ }^{\mathrm{i}}$ From Heymann et al. (1980).

j From Georges et al. (1999), Arthur, 2002 and Pourrut et al., 2005.

${ }^{k}$ From Bwaka et al. (1999), Guimard et al. (1999), Heymann et al. (1999), Khan et al. (1999) and Pourrut et al. (2005).

${ }^{1}$ From Arthur (2002), WHO, 2003a,b and http://www.who.int/mediacentre/factsheets/fs103/en/index1.html.

${ }^{m}$ From Arthur (2002), http://www.who.int/csr/don/2004_01_06/en/index.html and http://www.who.int/mediacentre/factsheets/fs103/ en/index1.html.

${ }^{\mathrm{n}}$ From http://www.who.int/csr/don/2005_06_16/en/index.html and http://www.who.int/mediacentre/factsheets/fs103/en/index1.html.

${ }^{\circ}$ From WHO (1978a,b), Bowen et al. (1980) and Richmond et al. (1983).

p From Baron et al. (1983).

${ }^{\mathrm{q}}$ From CDCP (2001b), WHO (2001) and Okware et al. (2002).

${ }^{\mathrm{r}}$ From http://www.who.int/csr/don/2004_08_07/en/index.html.

${ }^{s}$ From CDCP (1989), CDCP (1990) and Jahrling et al. (1990).

t From WHO (1992).

u From CDCP (1996), Miranda et al. (1999) and Rollin et al. (1999).

v From Le Guenno et al. (1995) and Formenty et al. (1999).

${ }^{w}$ From http://www.who.int/mediacentre/factsheets/fs103/en/index1.html. 
Table 5

Summary of filovirus vaccine efforts ${ }^{\mathrm{a}}$

\begin{tabular}{|c|c|c|c|c|c|}
\hline \multirow[t]{2}{*}{ Approach } & \multirow[t]{2}{*}{ Immunogen } & \multirow[t]{2}{*}{ Immunity } & \multicolumn{2}{|l|}{ Efficacy } & \multirow[t]{2}{*}{ Concerns } \\
\hline & & & Rodents & $\begin{array}{l}\text { Non-human } \\
\text { primates }\end{array}$ & \\
\hline
\end{tabular}

\section{Classical}

Killed $^{\mathrm{b}}$

Attenuated $^{\mathrm{c}}$

Subunit

Baculovirus $^{\mathrm{d}}$

$\mathrm{VLP}^{\mathrm{e}}$

Whole virus primates

$D N A$

$\begin{array}{ll}\text { Alone }^{\mathrm{f}} & \text { GP, NP }\end{array}$

Whole virus

$\operatorname{IgG}+$, low NT

Varies Failed

Potency, schedule, adjuvant, safety

$\operatorname{IgG}+$

Failed Failed

Safety

GP, GP $\Delta \mathrm{TM}$

$\mathrm{IgG}+$

Partial ND Potency, glycosylation

$\mathrm{GP}+\mathrm{VP} 40$

$\mathrm{IgG}+, \mathrm{NT}+, \mathrm{CD} 4+$

Good ND

Potency, schedule

Prime/boost with GP

$\begin{array}{llll}\mathrm{IgG}+ & \text { Poor } & \text { ND } & \text { Potency, schedule } \\ \mathrm{IgG}+\text {, no NT, CD4 }+ & \text { Good } & \text { Good } & \text { Schedule, potency }\end{array}$

Adenovirus ${ }^{\mathrm{g}}$

Vectored

Vaccinia ${ }^{\mathrm{h}}$

VRP/VEE ${ }^{\mathrm{i}}$

\section{GP, VP24}

(f)

Schedule, potency

Adenovirus $^{\mathrm{j}}$

GP, GP+NP, NP, VP35, VP30,

VP24

$\mathrm{IgG}+$, low NT

$\mathrm{GP}, \mathrm{GP}+\mathrm{NP}$

IgG+, no NT, CTL,

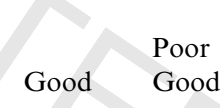

Anti-vector immunity, safety, potency

CD4+

$\mathrm{IgG}+, \mathrm{CD} 8+$

Anti-vector immunity, potency, schedule, heterologous

viruses

VSV $^{\mathrm{k}} \quad$ GP

Parainfluenzal ${ }^{\mathrm{l}}$

GP, GP+NP

$\mathrm{IgG}+$, no NT, no CMI

ND, not determined.

${ }^{a}$ Modified from Reed and Mohamadzadeh (2007).

${ }^{\text {b }}$ From Lupton et al. (1980), Ignatyev et al. (1996) and Warfield et al. (2004).

c From Bray et al. (2001).

${ }^{\mathrm{d}}$ From Hevey et al. (1997), Hevey et al. (2001) and Mellquist-Riemenschneider et al. (2003).

${ }^{\text {e }}$ From Bavari et al. (2002), Warfield et al. (2003), Swenson et al. (2004), Warfield et al. (2004), Swenson et al. (2005) and Warfield et al. (2005).

${ }^{\mathrm{f}}$ From Vanderzanden et al. (1998), Mellquist-Riemenschneider et al. (2003) and Riemenschneider et al. (2003).

g From Sullivan et al. (2000).

${ }^{\mathrm{h}}$ From Geisbert et al. (2002).

${ }^{i}$ From Pushko et al. (1997), Hevey et al. (1998), Pushko et al. (2000), Hevey et al. (2001), Wilson et al. (2001) and Olinger et al. (2005).

${ }^{\mathrm{j}}$ From Sullivan et al. (2003).

${ }^{\mathrm{k}}$ From Jones et al. (2005).

${ }^{1}$ From Bukreyev et al. (2006). 
by challenge with virulent Marburgvirus and the live vaccine, that had proven non-lethal in some strain of guinea pigs, on the contrary proved fatal in $20 \%$ of animals from another guinea pig strain (see Hevey et al., 2001; Reed and Mohamadzadeh, 2007).

Regarding vaccination strategies based on single or multiple filovirus proteins, most of the latest effort to develop vaccines have examined the protective capacity of GP, alone (Sullivan et al., 2000; Hevey et al., 2001; Rao et al., 2002; Riemenschneider et al., 2003; Mellquist-Riemenschneider et al., 2003; Jones et al., 2005; Wang et al., 2006a,b) or in association with both NP or VP40 (Swenson et al., 2004; Warfield et al., 2004; Swenson et al., 2005). The vaccine potential of other internal structural proteins has been investigated as well. VP24, VP30, and VP35 expressed by using recombinant Venezuelan equine encephalitis (VEE) vectors, have been shown to elicit some immunological response in rodents, but no single VP was able to confer complete protection against lethal Ebolavirus and Marburgvirus challenges (Hevey et al., 1998; Wilson et al., 2001). Previous investigation on rodents vaccinated with Ebolavirus VPs expressed by an alternative vector, recombinant Vaccinia, equally failed to elicit protective immunity (see Wilson et al., 2001). However, further investigations are needed before that the information obtained from this studies could be safely used for the development of a human vaccine. As a matter of fact, proof of vaccine concepts in rodent models may not necessarily forecast success in non-human primates and, by inference, in humans. Several vaccination strategies that were able to confer protective immunity to rodents, failed to protect non-human primates from robust challenge with Ebolavirus (Geisbert et al., 2002). However, the full protection from homologous filovirus infection obtained in non-human primates by using vaccination strategies based on Marburgvirus VEE replicons (Hevey et al., 1998), Ebolavirus adenovirus vectors (Sullivan et al., 2003), and Marburgvirus/Ebolavirus VSV (Jones et al., 2005) supports the results obtained in rodent models indicating that filovirus GPs are appropriate and perhaps sufficient components of vaccines, they can elicit both humoral and cellular specific response. Anyway, also the more effective vaccine can elicit only protection against heterologous strains from the same virus species, and ineffectual immune responses could be responsible of an immune-mediated exacerbation of disease progression in unprotected animal (see Swenson et al., 2005). Therefore a multivalent vaccine strategy is needed to obtain protection against all human pathogenic filovirus species (see Reed and Mohamadzadeh, 2007).

Multivalent DNA vaccine for Zaire ebolavirus, Sudan ebolavirus, and Ivory Coast ebolavirus has been shown to elicit a strong humoral response in rodents and protect animals against a lethal challenge with Zaire ebolavirus (Sullivan et al., 2000). A multiagent DNA vaccine for anthrax, VEE, Marburgvirus and Ebolavirus protected only about an half of the rodents challenged with either Marburgvirus or Ebolavirus (Riemenschneider et al., 2003). The possibility that multiagent immune protection could be elicited by using a VEE replicon-based vaccination strategy has been investigated as well. The results indicated that immune protection against Lassa and Ebolavirus could be developed in guinea pigs (see Pushko et al., 2001; Reed and Mohamadzadeh, 2007).

Although further investigation are needed and any positive results showed in rodents must obligatorily be confirmed in non-human primate models, the whole of the knowledge so far collected encourage us to believe that the development of a human vaccine is not so distant to be obtained (see Reed and Mohamadzadeh, 2007).

\section{Filoviruses as biological weapons}

The increased threat of terrorism necessitates an evaluation of the risk posed by various microorganisms as biological weapons. This is especially important in the case of the filoviruses. Ebolavirus and Marburgviruses, classified as Category A biowarfare agents, are considered as potential biological weapons because they pose a threat as lethal pathogens and because their use by terrorists might result in extreme fear and panic (see Borio et al., 2002; Bray, 2003).

An effective defense against filoviruses requires a comprehensive approach that includes the following elements: prevention of access to virus stocks, improved means of detection of deliberately induced disease outbreaks, rapid medical recognition of the viral haemorrhagic fever syndrome, rapid laboratory identification of filoviruses in patient specimens, prevention of person-to-person transmission, reliable decontamination procedures, development of effective vaccines, and development of effective antiviral therapy (see Borio et al., 2002; Bray, 2003). 
Although a variety of mechanisms are in place to protect the military and civilian populations of industrialized countries against infectious agents in food and water, it is impossible to provide them with a constant supply of purified air. The most dangerous form of biological warfare exploits this vulnerability (Bray, 2003).

There are reports about research projects really carried out in Soviet Union (now Russia) to weaponize Ebolavirus and Marburgvirus (CDCP, 2001a; Borio et al., 2002; http://cns.miis.edu/research/cbw/possess.htm). Using a monkey model, Soviet Union researchers have been able to demonstrate that also the inhalation of low concentration of infectious virus by aerosol is sufficient for the transmission of the disease (Bazhutin et al., 1992). So the respiratory route of transmission of weaponized filoviruses will add to the well known routes that characterized the way of viral spread in natural outbreaks (i.e., injection and direct contacts) (CDCP, 2001a). Alternatively, non-aerosolized material could be used to produce infection by contaminating surfaces, foods or beverages (see Borio et al., 2002; Bray, 2003).

If an aerosol attack with a filovirus goes undetected, at least a week will elapse before the onset of the first illnesses. By that time, no infectious virus will remain in the environment, and there will be no need for surface decontamination. Even if an aerosol attack is detected while still in progress or is discovered soon after completion, persons who have not actually inhaled the agent will be at negligible risk of infection from any residual aerosolized virus that might linger in the environment, since the few viral particles that might adhere to skin, clothing or surfaces would degrade within hours through the action of UV light. However, it would be prudent for people who may have been exposed to an aerosolized agent to take a full body shower with soap and to wash their clothing in hot water with detergent (see Borio et al., 2002; Bray, 2003).

Decontamination becomes a very important concern when virus-containing liquids or other materials are present, either as body fluids from sick patients or as residues from liquid suspensions employed to carry out a terrorist attack. Filoviruses may survive at room temperature in liquid or dried material for a number of days (Belanov et al., 1996). Steam sterilization is the most effective method of inactivating filoviruses. For the disinfection of surfaces and objects that are contaminated with blood or other body fluids, but cannot be sterilized by steam, the 'Centers for Disease Control and Prevention' recommends treatment with either a 1:100 dilution of household bleach or with any of the standard hospital disinfectants (see CDCP, 1995; CDCP, 1998; Bray, 2003).

Although some progress has been made in developing vaccines and antiviral drugs and terrorists might have great difficulty acquiring a filovirus for use as a weapon, public perception of a threat of epidemic spread could cause major social and economic disruption. A limited attack might thus achieve an impact out of proportion to the actual number of illnesses and deaths (see Bray, 2003).

\section{Conclusion and perspectives}

Ebolavirus and Marburgvirus overwhelm host defenses and cause disease by disregulating and defeating first the innate and then the adaptive immune systems of primates and humans. Ebola and Marburg haemorrhagic fevers appear as the result of accidental infection of human beings by agents that have evolved to survive in other animal species. In their reservoir hosts, filoviruses presumably cause mild, long-lasting, and probably non-fatal illness.

If host responses are important in determining the outcome of filoviral infection, then improvement or correction of those responses should be an effective therapeutic strategy. The addition of other types of therapy to block induction of increased vascular permeability and hypotension should also be beneficial. To elucidate how some people are able to mobilize protective responses and survive filovirus infection, while others die from overwhelming disease, study of the course of illness in patients in future outbreaks will be important. Detection of cases of mild or asymptomatic filoviral infection will also be important because it will provide the best means of identifying early host responses that can prevent development of severe disease.

The structural and functional characterization of Ebolavirus and Marburgvirus proteins as well as of filoviral ssRNA is a prerequisite to develop vaccines and specific drugs. Most of the effort to develop vaccines have examined the protective capacity of GP, alone or in association with both NP or VPs. The development of vaccines and therapies against Ebola and Marburg haemorrhagic fever is mandatory since these filovirus are considered as potential biological weapons. 
Authors wish to thank Prof. E. Affabris (Department of Biology, University 'Roma Tre', Roma, Italy) for helpful discussions and Mr. Angelo Merante for graphical assistance. This study was supported by grants from the Italian Ministry of Health (National Institute for Infectious Diseases I.R.C.C.S. 'Lazzaro Spallanzani', Ricerca corrente 2006).

\section{References}

Alazard-Dany, N., Volchkova, V., Reynard, O., Carbonnelle, C., Dolnik, O., Ottmann, M., Khromykh, A., Volchkov, V.E., 2006. Ebola virus glycoprotein GP is not cytotoxic when expressed constitutively at a moderate level. J. Gen. Virol. 87, $1247-1257$.

Arata, A.A., Johnson, B., 1978. Approaches toward studies on potential reservoirs of viral haemorrhagic fever in Southern Sudan - 1977 . In: Pattyn, S.R.S. (Ed.), Ebola Virus Haemorrhagic Fever. Elsevier, New York, pp. 185-189.

Arthur, R.R., 2002. Ebola in Africa: discoveries in the past decade. Euro. Surveill. 7, 33-36.

Baize, S., Leroy, E.M., Mavoungou, E., Fisher-Hoch, S.P., 2000. Apoptosis in fatal Ebola infection. Does the virus toll the bell for immune system? Apoptosis 5, 5-7.

Bamberg, S., Kolesnikova, L., Möller, P., Klenk, H.-D., Becker, S., 2005. VP24 of Marburg virus influences the formation of infectious particles. J. Virol. 79, 13421-13433.

Bär, S., Takada, A., Kawaoka, Y., Alizon, M., 2006. Detection of cell-cell fusion mediated by Ebola virus glycoproteins. J. Virol. 80, $2815-2822$.

Baron, R.C., McCormick, J.B., Zubeir, O.A., 1983. Ebola virus disease in southern Sudan: hospital dissemination and intrafamilial spread. Bull. World Health Organ. 61, 997-1003.

Barr, J.N., Whelan, S.P., Wertz, G.W., 2002. Transcriptional control of the RNA-dependent RNA polymerase of vesicular stomatitis virus. Biochim. Biophys. Acta 1577, 337-353.

Barrientos, L.G., O’Keefe, B.R., Bray, M., Sanchez, A., Gronenborn, A.M., Boyd, M.R., 2003. Cyanovirin-N binds to the viral surface glycoprotein, GP1,2 and inhibits infectivity of Ebola virus. Antiviral. Res. 58, 47-56.

Basler, C.F., Wang, X., Muhlberger, E., Volchkov, V., Paragas, J., Klenk, H.D., Garcia-Sastre, A., Palese, P., 2000. The Ebola virus VP35 protein functions as a type I IFN antagonist. Proc. Natl. Acad. Sci. USA 97, 12289-12294.

Basler, C.F., Mikulasova, A., Martinez-Sobrido, L., Paragas, J., Muhlberger, E., Bray, M., Klenk, H.D., Palese, P., Garcia-Sastre, A., 2003. The Ebola virus VP35 protein inhibits activation of interferon regulatory factor 3. J. Virol. 77, 7945-7956.

Bausch, D.G., Geisbert, T.W., 2007. Development of vaccines for Marburg hemorrhagic fever. Expert. Rev. Vaccines 6, 57-74.

Bausch, D.G., Borchert, M., Grein, T., Roth, C., Swanepoel, R., Libande, M.L., Talarmin, A., Bertherat, E., Muyembe-Tamfum, J.J., Tugume, B., Colebunders, R., Konde, K.M., Pirad, P., Olinda, L.L., Rodier, G.R., Campbell, P., Tomori, O., Ksiazek, T.G., Rollin, P.E., 2003. Risk factors for Marburg haemorrhagic fever, Democratic Republic of the Congo. Emerg. Inf. Dis. 9, $1531-1537$.

Bavari, S., Bosio, C.M., Wiegand, E., Ruthel, G., Will, A.B., Geisbert, T.W., Hevey, M., Schmaljohn, C., Aman, M.J., 2002. Lipid raft microdomains: a gateway for compartmentalized trafficking of Ebola and Marburg viruses. J. Exp. Med. 195, 593-602.

Bazhutin, N.B., Belanov, E.F., Spiridonov, V.A., Voitenko, A.V., Krivenchuk, N.A., Krotov, S.A., Omel'chenko, N.I., Tereshchenko, A.I., Khomichev, V.V., 1992. The effect of the methods for producing an experimental Marburg virus infection on the characteristics of the course of the disease in green monkeys. Vopr. Virusol. 37, 153-156.

Belanov, E.F., Muntianov, V.P., Kriuk, V.D., Sokolov, A.V., Bormotov, N.I., P'iankov, O.V., Sergeev, A.N., 1996. Survival of Marburg virus infectivity on contaminated surfaces and in aerosols. Vopr. Virusol. 41, 32-34.

Berman, H.M., Westbrook, J., Feng, Z., Gilliland, G., Bhat, T.N., Weissig, H., Shindyalov, I.N., Bourne, P.E., 2000. The protein data bank. Nucleic Acids Res. 28, 235-242.

Bieniasz, P.D., 2006. Late budding domains and host proteins in enveloped virus release. Virology 344, 55-63.

Borio, L., Inglesby, T., Peters, C.J., Schmaljohn, A.L., Hughes, J.M., Jahrling, P.B., Ksiazek, T., Johnson, K.M., Meyerhoff, A., O’Toole, T., Ascher, M.S., Bartlett, J., Breman, J.G., Eitzen Jr., E.M., Hamburg, M., Hauer, J., Henderson, D.A., Johnson, R.T., Kwik, G., Layton, M., Lillibridge, S., Nabel, G.J., Osterholm, M.T., Perl, T.M., Russell, P., Tonat, K., 2002. Haemorrhagic fever viruses as biological weapons: medical and public health management. JAMA 287, 2391-2405.

Bose, S., Banerjee, A.K., 2006. Viral defense mechanisms against interferon. In: Meager, A. (Ed.), The Interferons. Wiley-VCH Verlag GmbH \& Co. KgaA, Weinheim, pp. 227-273.

Bosio, C.M., Aman, M.J., Grogan, C., Hogan, R., Ruthel, G., Negley, D., Mohamadzadeh, M., Bavari, S., Schmaljohn, A., 2003. Ebola and Marburg viruses replicate in monocyte-derived dendritic cells without inducing the production of cytokines and full maturation. J. Infect. Dis. 188, 1630-1638.

Bowen, E.T., Platt, G.S., Lloyd, G., Raymond, R.T., Simpson, D.I., 1980. A comparative study of strains of Ebola virus isolated from southern Sudan and northern Zaire in 1976. J. Med. Virol. 6, 129-138.

Bray, M., 2003. Defense against filoviruses used as biological weapons. Antiviral Res. 57, 53-60.

Bray, M., Geisbert, T.W., 2005. Ebola virus: the role of macrophages and dendritic cells in the pathogenesis of Ebola haemorrhagic fever. Int. J. Biochem. Cell Biol. 37, 1560-1566.

Bray, M., Paragas, J., 2002. Experimental therapy of filovirus infections. Antiviral. Res. 54, 1-17.

Bray, M., Pilch, R., 2006. Filoviruses: recent advances and future challenges. Expert. Rev. Anti. Infect. Ther. 4, $917-921$. 
Bray, M., Hatfill, S., Hensley, L., Huggins, J.W., 2001. Haematological, biochemical and coagulation changes in mice, guinea-pigs and monkeys infected with a mouse-adapted variant of Ebola Zaire virus. J. Comp. Pathol. 125, 243-253.

Bukreyev, A., Yang, L., Zaki, S.R., Shieh, W.J., Rollin, P.E., Murphy, B.R., Collins, P.L., Sanchez, A., 2006. A single intranasal inoculation with a paramyxovirus-vectored vaccine protects guinea pigs against a lethal-dose Ebola virus challenge. J. Virol. 80, 22672279.

Bwaka, M.A., Bonnet, M.J., Calain, P., Colebunders, R., de Roo, A., Guimard, Y., Katwiki, K.R., Kibadi, K., Kipasa, M.A., Kuvula, K.J., Mapanda, B.B., Massamba, M., Mupapa, K.D., Muyembe-Tamfum, J.J., Ndaberey, E., Peters, C.J., Rollin, P.E., Van den Enden, E., 1999. Ebola haemorrhagic fever in Kikwit, Democratic Republic of the Congo: clinical observations in 103 patients. J. Infect. Dis. 179 (Suppl. 1), S1-S7.

Cardenas, W.B., Loo, Y.M., Gale, M., Hartman, A.L., Kimberlin, C.R., Martanez-Sobrido, L., Saphire, E.O., Basler, C.F., 2006. Ebola virus VP35 protein binds double-stranded RNA and inhibits alpha/beta interferon production induced by RIG-I signalling. J. Virol. $80,5168-5178$.

Centers for Disease Control and Prevention, 1989. Ebola virus infection in imported primates - Virginia, 1989. MMWR Morb. Mortal. Wkly Rep. 38, 831-832 (see also 837-838).

Centers for Disease Control and Prevention, 1990. Update: filovirus infection among persons with occupational exposure to nonhuman primates. Morb. Mortal. Wkly Rep. 39, 266-273.

Centers for Disease Control and Prevention, 1995. Update: management of patients with suspected viral hemorrhagic fever - United States. Morb. Mortal. Wkly Rep. 44, 475-479.

Centers for Disease Control and Prevention, 1996. Ebola-Reston virus infection among quarantined nonhuman primates - Texas, 1996. Morb. Mortal. Wkly Rep. 45, 314-316.

Centers for Disease Control and Prevention and World Health Organization, 1998. Infection control for viral hemorrhagic fevers in the African health care setting. Centers for Disease Control and Prevention, Atlanta, pp. 1-198.

Centers for Disease Control and Prevention, 2001a. Recognition of illness associated with the intentional release of a biologic agent. Morb. Mortal. Wkly Rep. 50, 893-897.

Centers for Disease Control and Prevention, 2001b. Outbreak of Ebola haemorrhagic fever, Uganda, August 2000-January 2001. Morb. Mortal. Wkly Rep. 50, 73-77.

Chandran, K., Sullivan, N.J., Felbor, U., Whelan, S.P., Cunningham, J.M., 2005. Endosomal proteolysis of the Ebola virus glycoprotein is necessary for infection. Science 308, 1643-1645.

Chan, S.Y., Speck, R.F., Ma, M.C., Goldsmith, M.A., 2000. Distinct mechanisms of entry by envelope glycoproteins of Marburg and Ebola (Zaire) viruses. J. Virol. 74, 4933-4937.

Colebunders, R., Sleurs, H., Pirard, P., Borchert, M., Libande, M., Mustin, J.P., Tshomba, A., Kinuani, L., Olinda, L.A., Tshioko, F., Muyembe-Tamfum, J.J., 2004. Organisation of health care during an outbreak of Marburg haemorrhagic fever in the Democratic Republic of Congo, 1999. J. Infect. 48, 347-353.

Conzelmann, K.K., 2004. Reverse genetics of Mononegavirales. Curr. Top. Microbiol. Immunol. 283, 1-41.

Dessen, A., Volchkov, V., Dolnik, O., Klenk, H.-D., Weissenhorn, W., 2000. Crystal structure of the matrix protein VP40 from Ebola virus. EMBO J. 19, 4228-4236.

Dey, M., Cao, C., Dar, A.C., Tamura, T., Ozato, K., Sicheri, F., Dever, T.E., 2005. Mechanistic link between PKR dimerization, autophosphorylation, and eIF2a substrate recognition. Cell 122, 901-913.

Dolnik, O., Volchkova, V., Garten, W., Carbonnelle, C., Becker, S., Kahnt, J., Ströher, U., Klenk, H.D., Volchkov, V., 2004. Ectodomain shedding of the glycoprotein GP of Ebola virus. EMBO J. 23, 2175-2184.

Ecker, D.J., Sampath, R., Willett, P., Wyatt, J.R., Samant, V., Massire, C., Hall, T.A., Hari, K., McNeil, J.A., Buchen-Osmond, C., Budowle, B., 2005. The Microbial Rosetta Stone Database: a compilation of global and emerging infectious microorganisms and bioterrorist threat agents. BMC Microbiol. 5, 19.

Falzarano, D., Krokhin, O., Wahl-Jensen, V., Seebach, J., Wolf, K., Schnittler, H.J., Feldmann, H., 2006. Structure-function analysis of the soluble glycoprotein, sGP, of Ebola virus. Chembiochem 7, 1605-1611.

Fass, D., Harrison, S.C., Kim, P.S., 1996. Retrovirus envelope domain at 1.7 A resolution. Nat. Struct. Biol. 3, 465-469.

Feldmann, H., Klenk, H.-D., 1996. Filoviruses. In: Baron, S. (Ed.), Medical Microbiology, fourth ed. University of Texas Medical Branch, Galveston, pp. 877-888.

Feldmann, H., Slenczka, W., Klenk, H.-D., 1996. Emerging and reemerging of filoviruses. Arch. Virol. (Suppl. 11), 77-100.

Feldmann, H., Jones, S., Klenk, H.-D., Schnittler, H.J., 2003. Ebola virus: from discovery to vaccine. Nat. Rev. Immunol. 3, 677-685.

Feldmann, H., Wahl-Jensen, V., Jones, S.M., Ströher, U., 2004. Ebola virus ecology: a continuing mistery. Trends Microbiol. $12,433-437$.

Feldmann, H., Jones, S.M., Schnittler, H.J., Geisbert, T., 2005. Therapy and prophylaxis of Ebola virus infections. Curr. Opin. Invest. Drugs 6, 823-830.

Feng, Z., Cerveny, M., Yan, Z., He, B., 2007. The VP35 protein of Ebola virus inhibits the antiviral effect mediated by double-stranded RNA-dependent protein kinase PKR. J. Virol. 81, 182-192.

Ferron, F., Longhi, S., Henrissat, B., Canard, B., 2002. Viral RNA-polymerases - a predicted 2'-O-ribose methyltransferase domain shared by all Mononegavirales. Trends Biochem. Sci. 27, 222-224.

Fields, B.N., Knipe, D.M., Howley, P.M., Chanock, R.M., Melnick, J.L., Monath, T.P., Roizman, B., Strauss, S.E. (Eds.), 1996. Fields Virology, third ed. Lippincott, Philadelphia, Pennsylvania.

Fisher, R.D., Chung, H.Y., Zhai, Q., Robinson, H., Sundquist, W.I., Hill, C.P., 2007. Structural and biochemical studies of ALIX/AIP1 and its role in retrovirus budding. Cell 128, 841-852.

Fisher-Hoch, S.P., 2005. Lessons from nosocomial viral haemorrhagic fever outbreaks. Br. Med. Bull., $123-137$. 
Formenty, P., Hatz, C., Le Guenno, B., Stoll, A., Rogenmoser, P., Widmer, A., 1999. Human infection due to Ebola virus, subtype Cote d'Ivoire: clinical and biologic presentation. J. Infect. Dis. 179 (Suppl. 1), S48-S53.

Francesconi, P., Yoti, Z., Declich, S., Onek, P.A., Fabiani, M., Olango, J., Andraghetti, R., Rollin, P.E., Opira, C., Greco, D., Salmaso, S., 2003. Ebola haemorrhagic fever transmission and risk factors of contacts, Uganda. Emerg. Inf. Dis. 9, $1430-1437$.

Gale, M. Jr., Blakely, C.M., Kwieciszewski, B., Tan, S.L., Dossett, M., Tang, N.M., Korth, M.J., Polyak, S.J., Gretch, D.R., Katze, M.G., 1998. Control of PKR protein kinase by hepatitis C virus nonstructural 5A protein: molecular mechanisms of kinase regulation. Mol. Cell. Biol. 18, 5208-5218.

Garcia-Sastre, A., Egorov, A., Matassov, D., Brandt, S., Levy, D.E., Durbin, J.E., Palese, P., Muster, T., 1998. Influenza A virus lacking the NS1 gene replicates in interferondeficient systems. Virology 252, 324-330.

Garoff, H., Hewson, R., Opstelten, D.-J.E., 1998. Virus maturation by budding. Microbiol. Mol. Biol. Rev. 62, 1171-1190.

Gear, J.S., Cassel, G.A., Gear, A.J., Trappler, B., Clausen, L., Meyers, A.M., Kew, M.C., Bothwell, T.H., Sher, R., Miller, G.B., Schneider, J., Koornhof, H.J., Gomperts, E.D., Isaacson, M., Gear, J.H., 1975. Outbreak of Marburg virus disease in Johannesburg. Br. Med. J. 4, 489-493.

Geisbert, T.W., Jahrling, P.B., 1995. Differentiation of filoviruses by electron microscopy. Virus Res. 39, $129-150$.

Geisbert, T.W., Jahrling, P.B., 2003. Towards a vaccine against Ebola virus. Expert. Rev. Vaccines 2, 777-789.

Geisbert, T.W., Pushko, P., Anderson, K., Smith, J., Davis, K.J., Jahrling, P.B., 2002. Evaluation in nonhuman primates of vaccines against Ebola virus. Emerg. Infect. Dis. 8, 503-507.

Geisbert, T.W., Young, H.A., Jahrling, P.B., Davis, K.J., Larsen, T., Kagan, E., Hensley, L.E., 2003. Pathogenesis of Ebola haemorrhagic fever in primate models: evidence that hemorrhage is not a direct effect of virus-induced cytolysis of endothelial cells. Am. J. Pathol. $163,2371-2382$.

Georges, A.J., Leroy, E.M., Renaut, A.A., Benissan, C.T., Nabias, R.J., Ngoc, M.T., Obiang, P.I., Lepage, J.P., Bertherat, E.J., Benoni, D.D., Wickings, E.J., Amblard, J.P., Lansoud-Soukate, J.M., Milleliri, J.M., Baize, S., Georges-Courbot, M.C., 1999. Ebola haemorrhagic fever outbreaks in Gabon, 1994-1997: epidemiologic and health control issues. J. Infect. Dis. 179 (Suppl. 1), S65-S75.

Germain, M., 1978. Collection of mammals and arthropods during the epidemic of haemorrhagic fever in Zaire. In: Pattyn, S.R.S. (Ed.), Ebola Virus Haemorrhagic Fever. Elsevier, New York, pp. 185-189.

Gomis-Ruth, F.X., Dessen, A., Timmins, J., Bracher, A., Kolesnikowa, L., Becker, S., Klenk, H.D., Weissenhorn, W., 2003. The matrix protein VP40 from Ebola virus octamerizes into pore-like structures with specific RNA binding properties. Structure 11, $423-433$.

Gruenberg, J., Stenmark, H., 2004. The biogenesis of multivesicular endosomes. Nat. Rev. Mol. Cell Biol. 5, 317-323.

Guimard, Y., Bwaka, M.A., Colebunders, R., Calain, P., Massamba, M., de Roo, A., Mupapa, K.D., Kibadi, K., Kuvula, K.J., Ndaberey, D.E., Katwiki, K.R., Mapanda, B.B., Nkuku, O.B., Fleerackers, Y., Van den Enden, E., Kipasa, M.A., 1999. Organisation of patient care during the Ebola epidemic in Kikwit, Democratic Republic of the Congo, 1995. J. Infect. Dis. 179 (Suppl. 1), S268S273.

Gupta, M., Mahanty, S., Ahmed, R., Rollin, P.E., 2001. Monocyte-derived human macrophages and peripheral blood mononuclear cells infected with ebola virus secrete MIP-1alpha and TNF-a and inhibit poly-IC-induced IFN-a in vitro. Virology 284, 20-25.

Han, Z., Harty, R.N., 2007. Influence of calcium/calmodulin on budding of Ebola VLPs: implications for the involvement of the Ras/Raf/ MEK/ERK pathway. Virus Genes. doi:10.1007/s11262-007-0125-9.

Han, Z., Boshra, H., Sunyer, J.O., Zwiers, S.H., Paragas, J., Harty, R.N., 2003. Biochemical and functional characterization of the Ebola virus VP24 protein: implications for a role in virus assembly and budding. J. Virol. 77, 1793-1800.

Han, Z., Licata, J.M., Paragas, J., Harty, R.N., 2007. Permeabilization of the plasma membrane by Ebola virus GP2. Virus Genes 34, 273281.

Hartlieb, B., Weissenhorn, W., 2006. Filovirus assembly and budding. Virology 344, 64-70.

Hartlieb, B., Modrof, J., Mühlberger, E., Klenk, H.D., Becker, S., 2003. Oligomerization of Ebola virus VP30 is essential for viral transcription and can be inhibited by a synthetic peptide. J. Biol. Chem. 278, 41830-41836.

Hartlieb, B., Muziol, T., Weissenhorn, W., Becker, S., 2007. Crystal structure of the C-terminal domain of Ebola virus VP30 reveals a role in transcription and nucleocapsid association. Proc. Natl. Acad. Sci. USA 104, 624-629.

Hartman, A.L., Towner, J.S., Nichol, S.T., 2004. A C-terminal basic amino acid motif of Zaire ebolavirus VP35 is essential for type I interferon antagonism and displays high identity with the RNA-binding domain of another interferon antagonist, the NS1 protein of influenza A virus. Virology 328, 177-184.

Hartman, A.L., Dover, J.E., Towner, J.S., Nichol, S.T., 2006. Reverse genetic generation of recombinant Zaire Ebola viruses containing disrupted IRF-3 inhibitory domains results in attenuated virus growth in vitro and higher levels of IRF-3 activation without inhibiting viral transcription or replication. J. Virol. 80, 6430-6440.

Harty, R.N., Brown, M.E., Wang, G., Hibregtse, J., Hayes, F.P., 2000. A PPxY motif within the VP40 protein of Ebola virus interacts physically and funtionally with a ubiquitin ligase: Implications for filovirus budding. Proc. Natl. Acad. Sci. USA 97, $13871-13876$.

Hennessen, W., 1971. Epidemiology of 'Marburg virus' disease. In: Martini, G.A., Siegert, R. (Eds.), Marburg Virus Disease. SpringerVerlag, Berlin, Heidelberg, New York, pp. 159-165.

Hensley, L.E., Young, H.A., Jahrling, P.B., Geisbert, T.W., 2002. Proinflammatory response during Ebola virus infection of primate models: possible involvement of the tumor necrosis factor receptor superfamily. Immunol. Lett. 80, 169-179.

Hensley, L.E., Jones, S.M., Feldmann, H., Jahrling, P.B., Geisbert, T.W., 2005. Ebola and Marburg viruses: pathogenesis and development of countermeasures. Curr. Mol. Med. 5, 761-772.

Hevey, M., Negley, D., Geisbert, J., Jahrling, P., Schmaljohn, A., 1997. Antigenicity and vaccine potential of Marburg virus glycoprotein expressed by baculovirus recombinants. Virology 239, 206-216. 
Hevey, M., Negley, D., Pushko, P., Smith, J., Schmaljohn, A., 1998. Marburg virus vaccines based upon alphavirus replicons protect guinea pigs and nonhuman primates. Virology 251, 28-37.

Hevey, M., Negley, D., VanderZanden, L., Tammariello, R.F., Geisbert, J., Schmaljohn, C., Smith, J.F., Jahrling, P.B., Schmaljohn, A.L., 2001. Marburg virus vaccines: comparing classical and new approaches. Vaccine 20, 586-593.

Hewlett, B.S., Amola, R.P., 2003. Cultural contexts of Ebola in northern Uganda. Emerg. Inf. Dis. 10, $1242-1248$.

Heymann, D.L., Weisfeld, J.S., Webb, P.A., Johnson, K.M., Cairns, T., Berquist, H., 1980. Ebola haemorrhagic fever: Tandala, Zaire, 1977-1978. J. Infect. Dis. 142, 372-376.

Heymann, D.L., Barakamfitiye, D., Szczeniowski, M., Muyembe-Tamfum, J.J., Bele, O., Rodier, G., 1999. Ebola haemorrhagic fever: lessons from Kikwit, Democratic Republic of the Congo. J. Infect. Dis. 179 (Suppl. 1), S283-S286.

Hoenen, T., Volchkov, V., Kolesnikova, L., Mittler, E., Timmins, J., Ottmann, M., Reynard, O., Becker, S., Weissenhorn, W., 2005. VP40 octamers are essential for Ebola virus replication. J. Virol. 79, 1898-1905.

Hoenen, T., Groseth, A., Falzarano, D., Feldmann, H., 2006a. Ebola virus: unravelling pathogenesis to combat a deadly disease. Trends Mol. Med. 12, 206-215.

Hoenen, T., Groseth, A., Kolesnikova, L., Theriault, S., Ebihara, H., Hartlieb, B., Bamberg, S., Feldmann, H., Stroher, U., Becker, S., 2006b. Infection of naive target cells with virus-like particles: implications for the function of ebola virus VP24. J. Virol. 80, 7260-7264.

Huang, Y., Xu, L., Sun, Y., Nabel, G.J., 2002. The assembly of Ebola virus nucleocapsid requires virion-associated proteins 35 and 24 and posttranslational modification of nucleoprotein. Mol. Cell 10, 307-316.

Ignatyev, G.M., Agafonov, A.P., Streltsova, M.A., Kashentseva, E.A., 1996. Inactivated Marburg virus elicits a nonprotective immune response in Rhesus monkeys. J. Biotechnol. 44, 111-118.

Isaäcson, M., 2001. Viral hemorrhagic fever hazards for travelers in Africa. Clin. Infect. Dis. 33, 1707-1712.

Jahrling, P.B., Geisbert, T.W., Dalgard, D.W., Johnson, E.D., Ksiazek, T.G., Hall, W.C., Peters, C.J., 1990. Preliminary report: isolation of Ebola virus from monkeys imported to USA. Lancet 335, 502-505.

Jahrling, P.B., Geisbert, T.W., Geisbert, J.B., Swearengen, J.R., Bray, M., Jaax, N.K., Huggins, J.W., LeDuc, J.W., Peters, C.J., 1999. Evaluation of immune globulin and recombinant interferon-a2b for treatment of experimental Ebola virus infections. J. Infect. Dis. 179 (Suppl. 1), S224-S234.

Jasenosky, L.D., Kawaoka, Y., 2004. Filovirus budding. Virus Res. 106, 181-188.

Jasenosky, L.D., Neumann, G., Lukashevich, I., Kawaoka, Y., 2001. Ebola virus VP40-induced particle formation and association with the lipid bilayer. J. Virol. 75, 5205-5214.

Jeffs, B., 2006. A clinical guide to viral haemorrhagic fevers: Ebola, Marburg and Lassa. Trop. Doct. 36, 1-4.

John, S.P., Wang, T., Steffan, S., Longhi, S., Schmaljohn, C.S., Jonsson, C.B., 2007. The Ebola virus VP30 is an RNA binding protein. J. Virol. doi:10.1128/JVI.02523-06.

Johnson, K.M., Lange, J.V., Webb, P.A., Murphy, F.A., 1977. Isolation and partial characterisation of a new virus causing acute haemorrhagic fever in Zaire. Lancet 1, 569-571.

Johnson, E., Jaax, N., White, J., Jahrling, P., 1995. Lethal experimental infections of rhesus monkeys by aerosolised Ebola virus. Int. J. Exp. Pathol. 76, 227-236.

Johnson, E.D., Johnson, B.K., Silverstein, D., Tukei, P., Geisbert, T.W., Sanchez, A.N., Jahrling, P.B., 1996. Characterization of a new Marburg virus isolated from a 1987 fatal case in Kenya. Arch. Virol. (Suppl. 11), 101-114.

Johnson, R.F., Bell, P., Harty, R.N., 2006a. Effect of Ebola virus proteins GP, NP and VP35 on VP40 VLP morphology. Virol. J. 233 , 31.

Johnson, R.F., McCarthy, S.E., Godlewski, P.J., Harty, R.N., 2006b. Ebola virus VP35-VP40 interaction is sufficient for packaging 3E5E minigenome RNA into virus-like particles. J. Virol. 80, 5135-5144.

Jones, S.M., Feldmann, H., Stroher, U., Geisbert, J.B., Fernando, L., Grolla, A., Klenk, H.D., Sullivan, N.J., Volchkov, V.E., Fritz, E.A., Daddario, K.M., Hensley, L.E., Jahrling, P.B., Geisbert, T.W., 2005. Live attenuated recombinant vaccine protects nonhuman primates against Ebola and Marburg viruses. Nat. Med. 11, 786-790.

Kane, A., Lloyd, J., Zafran, M., Simonsen, L., Kane, M., 1999. Transmission of hepatitis B, hepatitis C and human immunodeficiency viruses through unsafe injections in the developing world: model-based regional estimates. Bull. World Health Org. 77, 801-810.

Kash, J.C., Muhlberger, E., Carter, V., Grosch, M., Perwitasari, O., Proll, S.C., Thomas, M.J., Weber, F., Klenk, H.D., Katze, M.G., 2006. Global suppression of the host antiviral response by Ebola- and Marburgviruses: increased antagonism of the type I interferon response is associated with enhanced virulence. J. Virol. 80, 3009-3020.

Khan, A.S., Tshioko, K., Heymann, D.L., le Guenno, B., Nabeth, P., Kerstiens, B., Fleerackers, Y., Kilmarx, P.H., Rodier, G.R., Nkuku, O., Rollin, P.E., Sanchez, A., Zaki, S.R., Swanepoel, R., Tomori, O., Nichol, S.T., Peters, C.J., Muyembe-Tamfum, J.J., Ksiazek, T.G., 1999. The reemergence of Ebola haemorrhagic fever, Democratic Republic of the Congo, 1995. Commission de Lutte contre les Epidemies a Kikwit. J. Infect. Dis. (Suppl. 1), , S76-S8.

Kolesnikova, L., Becker, S., 2004. Virus maturation. In: Klenk, H.-D., Feldmann, H. (Eds.), Ebola and Marburg Viruses. Horizon Bioscience, Norfolk, pp. 171-203.

Kolesnikova, L., Mühlberger, E., Ryabchikova, E., Becker, S., 2000. Ultrastructural organization of recombinant Marburg virus nucleoprotein: comparison with Marburg virus inclusions. J. Virol. 74, 3899-3904.

Kolesnikova, L., Bamberg, S., Berghofer, B., Becker, S., 2004a. The matrix protein of Marburg virus is transported to the plasma membrane along cellular membranes: exploiting the retrograde late endosomal pathway. J. Virol. 78, 2382-2393.

Kolesnikova, L., Berghofer, B., Bamberg, S., Becker, S., 2004b. Multivesicular bodies as a platform for formation of the Marburg virus envelope. J. Virol. 78, 12277-12287.

Ksiazek, T.G., Rollin, P.E., Jahrling, P.B., Johnson, E., Dalgard, D.W., Peters, C.J., 1992. Enzyme immunosorbent assay for Ebola virus antigens in tissues of infected primates. J. Clin. Microbiol. 30, 947-950. 
Leffel, E.K., Reed, D.S., 2004. Marburg and Ebola viruses as aerosol threats. Biosecur. Bioterror. 2, 186-191.

Le Guenno, B., Formenty, P., Wyers, M., Gounon, P., Walker, F., Boesch, C., 1995. Isolation and partial characterization of a new strain of Ebola virus. Lancet 345, 1271-1274.

Le Guenno, B., Formenty, P., Boesch, C., 1999. Ebola virus outbreaks in the Ivory Coast and Liberia, 1994-1995. Curr. Top. Microbiol. Immunobiol. 235, 77-84.

Leirs, H., Mills, J.N., Krebs, J.W., Childs, J.E., Akaibe, D., Wollen, N., Ludwig, G., Peters, C.J., Ksiazek, TG., 1999. Search for the Ebola virus reservoir in Kikwit, Democratic Republic of the Congo: reflections on a vertebrate collection. J. Infect. Dis. 179, S155-S163.

Leroy, E.M., Baize, S., Volchkov, V.E., Fisher-Hoch, S.P., Georges-Courbot, M.C., Lansoud-Soukate, J., Capron, M., Debre, P., McCormick, J.B., Georges, A.J., 2000. Human asymptomatic Ebola infection and strong inflammatory response. Lancet 355, 21782179.

Leroy, E.M., Rouquet, P., Formenty, P., Souquiere, S., Kilbourne, A., Froment, J.M., Bermejo, M., Smit, S., Karesh, W., Swanepoel, R., Zaki, S.R., Rollin, P.E., 2004. Multiple Ebola virus transmission events and rapid decline of central African wildlife. Science 303, 387390.

Leroy, E.M., Kumulungui, B., Pourrut, X., Rouquet, P., Hassanin, A., Yaba, P., Delicat, A., Paweska, J.T., Gonzalez, J.P., Swanepoel, R., 2005. Fruit bats as reservoirs of Ebola virus. Nature 438, 575-576.

Licata, J.M., Simpson-Holley, M., Wright, N.T., Han, Z., Paragas, J., Harty, R.N., 2003. Overlapping motifs (PTAP and PPEY) within the Ebola virus VP40 protein function independently as late budding domains: involvement of host proteins TSG101 and VPS4. J. Virol. 77, 1812-1819.

Licata, J.M., Johnson, R.F., Han, Z., Harty, R.N., 2004. Contribution of Ebola virus glycoprotein, nucleoprotein, and VP24 to budding of VP40 virus-like particles. J. Virol. 78, 7344-7351.

Lupton, H.W., Lambert, R.D., Bumgardner, D.L., Moe, J.B., Eddy, G.A., 1980. Inactivated vaccine for Ebola virus efficacious in guineapig model. Lancet 2, 1294-1295.

Mahanty, S., Bray, M., 2004. Pathogenesis of filoviral haemorrhagic fevers. Lancet Infect. Dis. 4, 487-498.

Malashkevich, V.N., Schneider, B.J., McNally, M.L., Milhollen, M.A., Pang, J.X., Kim, P.S., 1999. Core structure of the envelope glycoprotein GP2 from Ebola virus at 1.9-A resolution. Proc. Natl. Acad. Sci. USA 96, 2662-2667.

Manicassamy, B., Wang, J., Jiang, H., Rong, L., 2005. Comprehensive analysis of ebola virus GP1 in viral entry. J. Virol. 79, 47934805 .

Manicassamy, B., Wang, J., Rumschlag, E., Tymen, S., Volchkova, V., Volchkov, V., Rong, L., 2007. Characterization of Marburg virus glycoprotein in viral entry. Virology $358,79-88$.

Martinez, O., Valmas, C., Basler, C.F., 2007. Ebola virus-like particle-induced activation of NF-kappaB and Erk signaling in human dendritic cells requires the glycoprotein mucin domain. Virology 364, 342-354.

Martini, G.A., 1969. Marburg agent disease: in man. Trans. R. Soc. Trop. Med. Hyg. 63, 295-302.

Martini, G.A., Knauff, H.G., Schmidt, H.A., Mayer, G., Baltzer, G., 1968. A hitherto unknown infectious disease contracted from monkeys. 'Marburg virus' disease. German Med. Monthly 13, 457-470.

Martin-Serrano, J., Perez-Caballero, D., Bieniasz, P.D., 2004. Context-dependent effects of L domains and ubiquitination on viral budding. J. Virol. 78, 5554-5563.

Marzi, A., Wegele, A., Pöhlmann, S., 2006a. Modulation of virion incorporation of Ebolavirus glycoprotein: effects on attachment, cellular entry and neutralization. Virology 352, 345-356.

Marzi, A., Akhavan, A., Simmons, G., Gramberg, T., Hofmann, H., Bates, P., Lingappa, V.R., Pöhlmann, S., 2006b. The signal peptide of the ebolavirus glycoprotein influences interaction with the cellular lectins DC-SIGN and DC-SIGNR. J. Virol. 80, 6305-6317.

Mavrakis, M., Kolesnikova, L., Schoehn, G., Becker, S., Ruigrok, R.W., 2002. Morphology of Marburg virus NP-RNA. Virology 296, 300-307.

Mellquist-Riemenschneider, J.L., Garrison, A.R., Geisbert, J.B., Saikh, K.U., Heidebrink, K.D., Jahrling, P.B., Ulrich, R.G., Schmaljohn, C.S., 2003. Comparison of the protective efficacy of DNA and baculovirus-derived protein vaccines for Ebola virus in guinea pigs. Virus Res. 92, 187-193.

Miranda, M.E., Ksiazek, T.G., Retuya, T.J., Khan, A.S., Sanchez, A., Fulhorst, C.F., Rollin, P.E., Calaor, A.B., Manalo, D.L., Roces, M.C., Dayrit, M.M., Peters, C.J., 1999. Epidemiology of Ebola (subtype Reston) virus in the Philippines, 1996. J. Infect. Dis. 179 (Suppl. 1), S115-S119.

Modrof, J., Muhlberger, E., Klenk, H.D., Becker, S., 2002. Phosphorylation of VP30 impairs ebola virus transcription. J. Biol. Chem. 277, 33099-33104.

Modrof, J., Becker, S., Muhlberger, E., 2003. Ebola virus transcription activator VP30 is a zinc-binding protein. J. Virol. 77, $3334-3338$

Mohamadzadeh, M., Chen, L., Schmaljohn, A.L., 2007. How ebola and Marburg viruses battle the immune system. Nat. Rev. Immunol. 7, 556-567.

Morita, E., Sundquist, W.I., 2004. Retrovirus budding. Ann. Rev. Cell Dev. Biol. 20, 395-425.

Mühlberger, E., Weik, M., Volchkov, V.E., Klenk, H.D., Becker, S., 1999. Comparison of the transcription and replication strategies of marburg virus and Ebola virus by using artificial replication systems. J. Virol. 73, 2333-2342.

Murphy, F.A., Peters, C.J., 1998. Ebola virus: where does it come from and where is it going? In: Krause, R.M. (Ed.), Emerging Infections: Biomedical Research Reports. Academic Press, San Diego, pp. 375-410.

Ndayimirije, N., Kindhauser, M.K., 2005. Marburg haemorrhagic fever in Angola-fighting fear and a lethal pathogen. N. Engl. J. Med. 352, 2155-2157.

Neumann, G., Ebihara, H., Takada, A., Noda, T., Kobasa, D., Jasenosky, L.D., Watanabe, S., Kim, J.H., Feldmann, H., Kawaoka, Y., 2005. Ebola virus VP40 late domains are not essential for viral replication in cell culture. J. Virol. 79, 10300-10307. 
Nguyen, T.L., Schoehn, G., Weissenhorn, W., Hermone, A.R., Burnett, J.C., Panchal, R.G., McGrath, C., Zaharevitz, D.W., Aman, M.J., Gussio, R., Bavari, S., 2005. An all-atom model of the pore-like structure of hexameric VP40 from Ebola: structural insights into the monomer-hexamer transition. J. Struct. Biol. 151, 30-40.

Nikiforov, V.V., Turovskii, Iu.I., Kalinin, P.P., Akinfeeva, L.A., Katkova, L.R., Barmin, V.S., Riabchikova, E.I., Popkova, N.I., Shestopalov, A.M., Nazarov, V.P., et al., 1994. A case of a laboratory infection with Marburg haemorrhagic fever. Zh. Mikrobiol. Epidemiol. Immunobiol. 3, 104-106.

Noda, T., Sagara, H., Suzuki, E., Takada, A., Kida, H., Kawaoka, Y., 2002. Ebola virus VP40 drives the formation of virus-like filamentous particles along with GP. J. Virol. 76, 4855-4865.

Noda, T., Aoyama, K., Sagara, H., Kida, H., Kawaoka, Y., 2005. Nucleocapsid-like structures of Ebola virus reconstructed using electron tomography. J. Vet. Med. Sci. 67, 325-328.

Noda, T., Watanabe, S., Sagara, H., Kawaoka, Y., 2007. Mapping of the VP40-binding regions of the nucleoprotein of Ebola virus. J. Virol. 81, 3554-3562.

Ogino, T., Banerjee, A.K., 2007. Unconventional mechanism of mRNA capping by the RNA-dependent RNA polymerase of vesicular stomatitis virus. Mol. Cell. 25, 85-97.

Okware, S.I., Omaswa, F.G., Zaramba, S., Opio, A., Lutwama, J.J., Kamugisha, J., Rwaguma, E.B., Kagwa, P., Lamunu, M., 2002. An outbreak of Ebola in Uganda. Trop. Med. Int. Health 7, 1068-1075.

Olinger, G.G., Bailey, M.A., Dye, J.M., Bakken, R., Kuehne, A., Kondig, J., Wilson, J., Hogan, R.J., Hart, M.K., 2005. Protective cytotoxic T-cell responses induced by venezuelan equine encephalitis virus replicons expressing Ebola virus proteins. J. Virol. 79, 14189-14196.

Panchal, R.G., Ruthel, G., Kenny, T.A., Kallstrom, G.H., Lane, D., Badie, S.S., Li, L., Bavari, S., Aman, M.J., 2003. In vivo oligomerization and raft localization of Ebola virus protein VP40 during vesicular budding. Proc. Natl. Acad. Sci. USA 100, 1593615941.

Paragas, J., Geisbert, T.W., 2006. Development of treatment strategies to combat Ebola and Marburg viruses. Expert. Rev. Anti Infect. Ther. 4, 67-76.

Peters, C.J., 2005. Marburg and Ebola-arming ourselves against the deadly filoviruses. N. Eng. J. Med. 352, $2571-2573$.

Peterson, A.T., Bauer, J.T., Mills, J.N., 2004a. Ecologic and geographic distribution of filovirus disease. Emerg. Inf. Dis. $10,40-47$.

Peterson, A.T., Carroll, D.S., Mills, J.N., Johnson, K.M., 2004b. Potential mammalian filovirus reservoirs. Emerg. Inf. Dis. 10, 20732081.

Pettersen, E.F., Goddard, T.D., Huang, C.C., Couch, G.S., Greenblatt, D.M., Meng, E.C., Ferrin, T.E., 2004. UCSF Chimera - a visualization system for exploratory research and analysis. J. Comput. Chem. 25, 1605-1612.

Pigott, D.C., 2005. Hemorrhagic fever viruses. Crit. Care Clin. 21, 765-783.

Pourrut, X., Kumulungui, B., Wittmann, T., Moussavou, G., Delicat, A., Yaba, P., Nkoghe, D., Gonzalez, J.P., Leroy, E.M., 2005. The natural history of Ebola virus in Africa. Microbes Infect. 7, 1005-1014.

Pushko, P., Parker, M., Ludwig, G.V., Davis, N.L., Johnston, R.E., Smith, J.F., 1997. Replicon-helper systems from attenuated Venezuelan equine encephalitis virus: expression of heterologous genes in vitro and immunization against heterologous pathogens in vivo. Virology 239, 389-401.

Pushko, P., Bray, M., Ludwig, G.V., Parker, M., Schmaljohn, A., Sanchez, A., Jahrling, P.B., Smith, J.F., 2000. Recombinant RNA replicons derived from attenuated Venezuelan equine encephalitis virus protect guinea pigs and mice from Ebola haemorrhagic fever virus. Vaccine 19, 142-153.

Pushko, P., Geisbert, J., Parker, M., Jahrling, P., Smith, J., 2001. Individual and bivalent vaccines based on alphavirus replicons protect guinea pigs against infection with Lassa and Ebola viruses. J. Virol. 75, 11677-11685.

Rao, M., Bray, M., Alving, C.R., Jahrling, P., Matyas, G.R., 2002. Induction of immune responses in mice and monkeys to Ebola virus after immunization with liposome-encapsulated irradiated Ebola virus: protection in mice requires CD4 ${ }^{+} \mathrm{T}$ cells. J. Virol. 76 , 91769185.

Reed, D.S., Mohamadzadeh, M., 2007. Status and challenges of filovirus vaccines. Vaccine 25, 1923-1934.

Reid, S.P., Cardenas, W.B., Basler, C.F., 2005. Homo-oligomerization facilitates the interferon-antagonist activity of the ebolavirus VP35 protein. Virology 341, 179-189.

Reid, S.P., Leung, L.W., Hartman, A.L., Martinez, O., Shaw, M.L., Carbonnelle, C., Volchkov, V.E., Nichol, S.T., Basler, C.F., 2006. Ebola virus VP24 binds karyopherin alpha1 and blocks STAT1 nuclear accumulation. J. Virol. 80, 5156-5167.

Richmond, D.D., Cleveland, P.H., McCormick, J.B., Johnson, K.M., 1983. Antigenic analysis of strains of Ebola virus: identification of two Ebola virus serotypes. J. Infect. Dis. 147, 268-271.

Riemenschneider, J., Garrison, A., Geisbert, J., Jahrling, P., Hevey, M., Negley, D., Schmaljohn, A., Lee, J., Hart, M.K., Vanderzanden, L., Custer, D., Bray, M., Ruff, A., Ivins, B., Bassett, A., Rossi, C., Schmaljohn, C., 2003. Comparison of individual and combination DNA vaccines for B. anthracis, Ebola virus, Marburg virus and Venezuelan equine encephalitis virus. Vaccine 21, $4071-4080$.

Rollin, P.E., Williams, R.J., Bressler, D.S., Pearson, S., Cottingham, M., Pucak, G., Sanchez, A., Trappier, S.G., Peters, R.L., Greer, P.W., Zaki, S., Demarcus, T., Hendricks, K., Kelley, M., Simpson, D., Geisbert, T.W., Jahrling, P.B., Peters, C.J., Ksiazek, T.G., 1999. Ebola (subtype Reston) virus among quarantined nonhuman primates recently imported from the Philippines to the United States. J. Infect. Dis. 179 (Suppl. 1), S108-S114.

Rouquet, P., Froment, J.M., Bermejo, M., Yaba, P., Delicat, A., Rollin, P.E., Leroy, E.M., 2005. Wild animal mortality monitoring and human Ebola outbreaks, Gabon and Republic of Congo, 2001-2003. Emerg. Infect. Dis. 11, 283-290.

Ruigrok, R.W.H., Schon, G., Dessen, A., Forest, E., Volchkov, V., Dolnik, O., Klenk, H.-D., Weissenhorn, W., 2000a. Structural charactyerization and membrane binding properties of the matrix protein VP40 of Ebola. J. Mol. Biol. 300, $103-112$. 
Ruthel, G., Demmin, G.L., Kallstrom, G., Javid, M.P., Badie, S.S., Will, A.B., Nelle, T., Schokman, R., Nguyen, T.L., Carra, J.H., Bavari, S., Aman, M.J., 2005. Association of Ebola virus matrix protein VP40 with microtubules. J. Virol. 79, 4709-4719.

Salvaggio, M.R., Baddley, J.W., 2004. Other viral bioweapons: Ebola and Marburg hemorrhagic fever. Dermatol. Clin. 22, $291-302$.

Schibli, D.J., Weissenhorn, W., 2004. Class I and class II viral fusion protein structures reveal similar principles in membrane fusion. Mol. Membr. Biol. 21, 361-371.

Schmitt, A.P., Lamb, R.A., 2004. Escaping from the cell: assembly and budding of negative-strand RNA viruses. Curr. Top. Microbiol Immunol. 283, 145-196.

Schornberg, K., Matsuyama, S., Kabsch, K., Delos, S., Bouton, A., White, J., 2006. Role of endosomal cathepsins in entry mediated by the Ebola virus glycoprotein. J. Virol. 80, 4174-4178.

Scianimanico, S., Schoehn, G., Timmins, J., Ruigrok, R.H., Klenk, H.D., Weissenhorn, W., 2000. Membrane association induces a conformational change in the Ebola virus matrix protein. EMBO J. 19, 6732-6741.

Siegert, R., Shu, H.L., Slenczka, W., Peters, D., Muller, G., 1967. Zur Aetiologie einer unbekannten, von Affen ansgegangen menschlichen Infektionskrankheit. Dtsch. Med. Wochenschr. 92, 2341-2343.

Smith, D.H., Johnson, B.K., Isaacson, M., Swanapoel, R., Johnson, K.M., Killey, M., Bagshawe, A., Siongok, T., Keruga, W.K., 1982. Marburg-virus disease in Kenya. Lancet 1, 816-820.

Stille, W., Bohle, E., Helm, E., van Rey, W., Siede, W., 1968. An infectious disease transmitted by Cercopithecus aethiops (Green-Monkey disease). German Med. Monthly 13, 470-478.

Stroher, U., Feldmann, H., 2006. Progress towards the treatment of Ebola haemorrhagic fever. Expert. Opin. Invest. Drugs 15, 1523-1535.

Su, Q., Wang, S., Baltzis, D., Qu, L.K., Wong, A.H., Koromilas, A.E., 2006. Tyrosine phosphorylation acts as a molecular switch to fullscale activation of the eIF2a RNA-dependent protein kinase. Proc. Natl. Acad. Sci. USA 103, 63-68.

Sullivan, N.J., Sanchez, A., Rollin, P.E., Yang, Z.Y., Nabel, G.J., 2000. Development of a preventive vaccine for Ebola virus infection in primates. Nature 408, 605-609.

Sullivan, N.J., Geisbert, T.W., Geisbert, J.B., Xu, L., Yang, Z.Y., Roederer, M., Koup, R.A., Jahrling, P.B., Nabel, G.J., 2003. Accelerated vaccination for Ebola virus haemorrhagic fever in non-human primates. Nature 424, 681-684.

Sullivan, N.J., Peterson, M., Yang, Z.Y., Kong, W.P., Duckers, H., Nabel, E., Nabel, G.J., 2005. Ebola virus glycoprotein toxicity is mediated by a dynamin-dependent protein-trafficking pathway. J. Virol. 79, 547-553.

Swenson, D.L., Warfield, K.L., Kuehl, K., Larsen, T., Hevey, M.C., Schmaljohn, A., Bavari, S., Aman, M.J., 2004. Generation of Marburg virus-like particles by co-expression of glycoprotein and matrix protein. FEMS Immunol. Med. Microbiol. 40, $27-31$.

Swenson, D.L., Warfield, K.L., Negley, D.L., Schmaljohn, A., Aman, M.J., Bavari, S., 2005. Virus-like particles exhibit potential as a panfilovirus vaccine for both Ebola and Marburg viral infections. Vaccine 23, 3033-3042.

Takada, A., Kawaoka, Y., 2001. The pathogenesis of Ebola haemorrhagic fever. Trends Microbiol. 9, 506-511.

Todorovitch, K., Mocitch, M., Klasjna, R., 1971. Clinical picture of two patients infected by the Marburg vervet virus. In: Martini, G.A., Siegert, R. (Eds.), Marburg Virus Disease. Springer-Verlag, Berlin, Heidelberg, New York, pp. 19-23.

Towner, J.S., Rollin, P.E., Bausch, D.G., Sanchez, A., Crary, S., Vincent, M., Lee, W.F., Spiropoulou, C.F., Ksiazek, T.G., Lukwiya, M., Kaducu, F., Downing, R., Nichol, S.T., 2004. Rapid diagnosis of Ebola haemorrhagic fever by reverse transcription PCR in an outbreak setting and assessment of patient viral load as a predictor of outcome. J. Virol. 78, 4330-4341.

Urata, S., Noda, T., Kawaoka, Y., Morikawa, S., Yokosawa, H., Yasuda, J., 2007. Interaction of Tsg101 with Marburg virus VP40 depends on the PPPY motif, but not the PT/SAP motif as in the case of Ebola virus, and Tsg101 plays a critical role in the budding of Marburg virus-like particles induced by VP40, NP, and GP. J. Virol. 81, 4895-4899.

Vanderzanden, L., Bray, M., Fuller, D., Roberts, T., Custer, D., Spik, K., Jahrling, P., Huggins, J., Schmaljohn, A., Schmaljohn, C., 1998. DNA vaccines expressing either the GP or NP genes of Ebola virus protect mice from lethal challenge. Virology 246, $134-144$.

Volchkov, V.E., Blinov, V.M., Netesov, S.V., 1992. The envelope glycoprotein of Ebola virus contains an immunosuppressive-like domain similar to oncogenic retroviruses. FEBS Lett. 305, 181-184.

Volchkov, V.E., Feldmann, H., Volchkova, V.A., Klenk, H.D., 1998. Processing of the Ebola virus glycoprotein by the proprotein convertase furin. Proc. Natl. Acad. Sci. USA 95, 5762-5767.

Volchkov, V.E., Volchkova, V.A., Chepurnov, A.A., Blinov, V.M., Dolnik, O., Netesov, S.V., Feldmann, H., 1999. Characterization of the L gene and $5^{\prime}$ trailer region of Ebola virus. J. Gen. Virol. 80, 355-362.

Wahl-Jensen, V.M., Afanasieva, T.A., Seebach, J., Stroher, U., Feldmann, H., Schnittler, H.J., 2005. Effects of Ebola virus glycoproteins on endothelial cell activation and barrier function. J. Virol. 79, 10442-10450.

Wang, D., Schmaljohn, A.L., Raja, N.U., Trubey, C.M., Juompan, L.Y., Luo, M., Deitz, S.B., Yu, H., Woraratanadharm, J., Holman, D.H., Moore, K.M., Swain, B.M., Pratt, W.D., Dong, J.Y., 2006a. De novo syntheses of Marburg virus antigens from adenovirus vectors induce potent humoral and cellular immune responses. Vaccine 24, 2975-2986.

Wang, D., Hevey, M., Juompan, L.Y., Trubey, C.M., Raja, N.U., Deitz, S.B., Woraratanadharm, J., Luo, M., Yu, H., Swain, B.M., Moore, K.M., Dong, J.Y., 2006b. Complex adenovirus-vectored vaccine protects guinea pigs from three strains of Marburg virus challenges. Virology 353, 324-332.

Warfield, K.L., Bosio, C.M., Welcher, B.C., Deal, E.M., Mohamadzadeh, M., Schmaljohn, A., Aman, M.J., Bavari, S., 2003. Ebola viruslike particles protect from lethal Ebola virus infection. Proc. Natl. Acad. Sci. USA 100, 15889-15894.

Warfield, K.L., Swenson, D.L., Negley, D.L., Schmaljohn, A.L., Aman, M.J., Bavari, S., 2004. Marburg virus-like particles protect guinea pigs from lethal Marburg virus infection. Vaccine 22, 3495-3502.

Warfield, K.L., Swenson, D.L., Demmin, G., Bavari, S., 2005. Filovirus-like particles as vaccines and discovery tools. Expert. Rev. Vaccines 4, 429-440.

Watanabe, S., Noda, T., Kawaoka, Y., 2006. Functional mapping of the nucleoprotein of Ebola virus. J. Virol. 80, $3743-3751$. 
Weik, M., Modrof, J., Klenk, H.D., Becker, S., Mühlberger, E., 2002. Ebola virus VP30-mediated transcription is regulated by RNA secondary structure formation. J. Virol. 76, 8532-8539.

Weissenhorn, W., Carfi, A., Lee, K.H., Skehel, J.J., Wiley, D.C., 1998. Crystal structure of the Ebola virus membrane fusion subunit, GP2, from the envelope glycoprotein ectodomain. Mol. Cell. 2, 605-616.

Wilson, J.A., Bray, M., Bakken, R., Hart, M.K., 2001. Vaccine potential of Ebola virus VP24, VP30, VP35, and VP40 proteins. Virology 286, 384-390.

Wong, S., Lau, S., Woo, P., Yuen, K.Y., 2007. Bats as a continuing source of emerging infections in humans. Rev. Med. Virol. 17, 67-91.

World Health Organization, 1978a. Ebola haemorrhagic fever in Sudan, 1976. Bull. World Health Organ. 56, $247-270$.

World Health Organization, 1978b. Ebola haemorrhagic fever in Zaire, 1976. Bull. World Health Organ. 56, $271-293$.

World Health Organization, 1992. Viral haemorrhagic fever in imported monkeys. Wkly Epidemiol. Rec. 67, $142-143$.

World Health Organization, 1999. Viral haemorrhagic fever/Marburg, Democratic Republic of the Congo. Wkly Epidemiol. Rec. 74, 157158.

World Health Organization, 2001. Outbreak of Ebola haemorrhagic fever, Uganda, August 2000-January 2001. Wkly Epidemiol. Rec. 76, $41-46$.

World Health Organization, 2003a. Outbreak(s) of Ebola haemorrhagic fever in the Republic of the Congo, October $2001-\mathrm{July} 2002$. Wkly Epidemiol. Rec. 78, 217-228.

World Health Organization, 2003b. Outbreak(s) of Ebola haemorrhagic fever in the Republic of the Congo, January-April 2003. Wkly Epidemiol. Rec. 78, 285-295.

Zaki, S.R., Shieh, W.J., Greer, P.W., Goldsmith, C.S., Ferebee, T., Katshitshi, J., Tshioko, F.K., Bwaka, M.A., Swanepoel, R., Calain, P., Khan, A.S., Lloyd, E., Rollin, P.E., Ksiazek, T.G., Peters, C.J., 1999. A novel immunohistochemical assay for the detection of Ebola virus in skin: implications for diagnosis, spread and surveillance of Ebola haemorrhagic fever. Commission de Lutte contre les Epidemies a Kikwit. J. Infect. Dis. 179 (Suppl. 1), S36-S47.

Zampieri, C.A., Fortin, J.F., Nolan, G.P., Nabel, G.J., 2007. The ERK mitogen-activated protein kinase pathway contributes to Ebola virus glycoprotein-induced cytotoxicity. J. Virol. 81, 1230-1240.

\section{Internet websites}

Center for Nonproliferation Studies. Chemical and biological weapons: possession and programs past and present. Available at: http:// cns.miis.edu/research/cbw/possess.htm.

European Molecular Biology Laboratory. European Bioinformatics Institute. ClustalW. Available at: http://www.ebi.ac.uk/clustalw/ index.html.

Global Polio Eradication Initiative. Available at: http://www.polioeradication.org/.

National Center for Biotechnology Information, National Library of Medicine, National Institutes of Health. Basic logical alignment search tool (BLAST). Available at: http://www.ncbi.nlm.nih.gov/BLAST/.

National Center for Biotechnology Information, National Library of Medicine, National Institutes of Health. Ebola virus genome. Available at: http://www.ncbi.nlm.nih.gov/entrez/query.fcgi?CMD=search\&DB=pubmed.

National Center for Biotechnology Information, National Library of Medicine, National Institutes of Health. Filovirus protein. Available at: http://www.ncbi.nlm.nih.gov/entrez/query.fcgi?CMD=search\&DB=protein.

Stanford University. Brief General History of Ebola. Available at: http://virus.stanford.edu/filo/history.html.

The United Nations Children's Fund - The state of the world's children, 2006. Available at: http://www.unicef.org/sowc06/intro.html.

The Universal Virus Database of the International Committee on Taxonomy of Viruses. Available at: http://www.ncbi.nlm.nih.gov/ $\mathrm{ICTVdb/ICTVdB/.}$

United Nations World Food Programme. Available at: http://www.wfp.org/Country_Brief/Hunger_Map/map/.

University of California at Davis. Ebola virus cell surface. Available at: http://www.ncbi.nlm.nih.gov/ICTVdb/Images/Murphy/ ebola_cell.htm.

World Health Organization. Ebola haemorrhagic fever - chronology. Available at: http://www.who.int/mediacentre/factsheets/fs103/en/ index 1.html.

World Health Organization. Ebola haemorrhagic fever in the Republic of the Congo - update 6. 6 January 2004. Available at: http:// www.who.int/csr/don/2004_01_06/en/index.html.

World Health Organization. Fièvre hémorragique à Virus Ebola: Le Congo a maitrisé la troisième épidémie dans des délais acceptables. La Missive de l'OMS - Congo, No. 006, fev-mars 04. Available at: http://www.who.int/csr/disease/ebola/ebolacongofr.pdf.

World Health Organization. WHO announces end of Ebola outbreak in southern Sudan. 7 August 2004. Available at: http://www.who.int/ csr/don/2004_08_07/en/index.html.

World Health Organization. Ebola haemorrhagic fever in the Republic of the Congo - update 2. 16 June 2005. Available at: http:// www.who.int/csr/don/2005_06_16/en/index.html.

World Health Organization. Marburg haemorrhagic fever in Angola - update 25. 24 August 2005. Available at: http://www.who.int/csr/ don/2005_08_24/en/index.html. 